\title{
LLEGADA DE LAS AMPOLLETAS INYECTABLES A MÉXICO Y ESTADOS UNIDOS \\ DIFERENCIAS Y SIMILITUDES EN LA PRÁCTICA FARMACÉUTICA \\ (1896-1939)
}

\author{
ARRIVAL OF INJECTION AMPOULES INTO MEXICO \\ AND THE UNITED STATES
}

DIFFERENCES AND SIMILARITIES IN PHARMACEUTICAL PRACTICE

(1896-1939)

\author{
Rogelio Godínez Reséndiz \\ Universidad Autónoma Metropolitana, Unidad Xochimilco \\ Departamento de Sistemas Biológicos \\ rgodinez_uam@yahoo.com

\section{Liliana Schifter ACEves} \\ Universidad Autónoma Metropolitana, Unidad Xochimilco \\ Departamento de Sistemas Biológicos
}

\section{Mariana OrTIZ ReYNOSO}

Universidad Autónoma del Estado de México

Facultad de Química

\section{Resumen}

A finales del siglo xıx y principios del xx, las ampolletas inyectables llegaron a México y Estados Unidos con recibimientos distintos por parte de los farmacéuticos locales. Mientras que en México la recepción de las ampolletas fue favorable, en Estados Unidos fueron acogidas con desconfianza, lo que dio lugar a diferencias importantes en su desarrollo y manufactura en ambos países. El objetivo de este trabajo es analizar las divergencias y similitudes que tuvieron los procesos de introducción de las ampolletas inyectables en México y Estados Unidos. Se busca mostrar que la adopción de las ampolletas fue influenciada por los modelos terapéuticos y de industrialización del medicamento que prevalecían durante la época, los cuales determinaron las características principales de la profesión y la práctica farmacéutica en cada nación.

Palabras clave: ampolletas inyectables, México, Estados Unidos, siglo xIx, siglo xx, farmacéuticos, historia de la farmacia, historia de la tecnología, historia de la ciencia.

\footnotetext{
Abstract

At the end of the 19th and the beginning of the 20th century, injection ampoules were introduced in Mexico and the United States having different perceptions from local pharmacists. While in Mexico the ampoules reception was favorable, in the United States they were received with disbelief. This caused important differences on ampoules production and popularization in the mentioned countries. The aim of this paper is to analyze the divergences and similarities within the kick off of processing injection ampoules in Mexico and the United States. It is evidenced that these processes were influenced by both therapeutic and
} 
drug manufacturing models of the time, which also determined most of main characteristics of the pharmaceutical profession in each nation.

Keywords: injection ampoules, Mexico, United States, 19th century, 20th century, pharmacists, history of pharmacy, history of science, history of technology.

Información del artículo

Recibido: 12 de febrero 2019.

Aceptado: 5 de abril de 2019.

DOI: $10.22201 /$ iih.24485004e.2019.57.68411

\section{Introducción}

La utilización de cristal para transportar y envasar productos farmacéuticos líquidos y sólidos comenzó durante el siglo XVIII. Sin embargo, el uso práctico de este material se extendió cuando las inyecciones medicinales (por vía subcutánea o intravenosa) empezaron a ganar popularidad en la segunda mitad del XIX. En las postrimerías del siglo decimonónico, diversas farmacopeas ya señalaban los requerimientos que debían tener los viales de cristal utilizados para almacenar sustancias farmacéuticas, así como la coloración del vidrio necesaria para proteger fármacos fotosensibles. ${ }^{1}$ Por ejemplo, hacia 1880 los compuestos de plata con efecto terapéutico tenían que preservarse en viales de color ámbar u oscuros, lo que motivó a numerosos fabricantes a comercializar esta clase de envases. Las diversas coloraciones del cristal se lograban mediante la adición de elementos como hierro, azufre o manganeso. ${ }^{2}$

De igual forma, en las últimas décadas del siglo xıx, se lograron grandes avances en los campos de la bacteriología y la microbiología y en la aplicación de procesos novedosos como la esterilización y la asepsia. Gracias a los trabajos de Louis Pasteur y de diversos científicos, se comprendió la importancia de prevenir la contaminación microbiana en todos aquellos productos farmacéuticos parenterales (es decir, que se administraban mediante inyección en el ser humano y en algunos animales). Es importante señalar que la esterilización consistía en eliminar todos los microorganis-

${ }^{1}$ Robert A. Schaut y W. Porter Weeks, "Historical Review of Glasses Used for Parenteral Packaging”, Journal of Pharmaceutical Science and Technology, v. 71, n. 4, 2017, p. 279-296.

${ }^{2}$ National Convention for Revising the Pharmacopoeia, The Pharmacopoeia of the United States of America, sixth decennial revision, New York, William Wood \& Company, 1883, p. 46. 
mos, fueran patógenos o no, presentes en un medio determinado. Por otra parte, en la asepsia sólo se trataba de destruir o impedir la multiplicación de formas de vida patógenas. ${ }^{3}$

Desde entonces, la esterilización se convirtió en una operación unitaria indispensable para la producción de soluciones farmacéuticas inyectables. Naturalmente, el dominio de este proceso quedó a cargo del profesional farmacéutico, dado que era el experto en el diseño, fabricación y uso de presentaciones medicinales. Para asegurar la calidad de los medicamentos, este profesional tuvo que incluir en su formación curricular conocimientos en bacteriología y microbiología, así como tópicos relativos a los procesos fisicoquímicos involucrados. De igual forma, debía controlar variables tecnológicas debido a la introducción en estos campos de nuevos equipos y aparatos industriales que se desarrollarían y perfeccionarían al paso de los años.

En 1886, el farmacéutico francés Stanislus Limousin sugirió la utilización de un nuevo envase de cristal para almacenar preparaciones estériles, al cual llamó ampoule (ampolleta). Ésta consistía en un bulbo esférico con una capacidad un poco mayor a un centímetro cúbico y un cuello de 1.25 pulgadas de largo. ${ }^{4}$ En los años siguientes, los farmacéuticos franceses fueron los pioneros en el desarrollo de la ampolleta, destinada a contener desde formulaciones inyectables hasta vacunas humanas y veterinarias. Las ventajas de esta presentación consistían en lo siguiente: proporcionaba soluciones estériles para uso inmediato cuando no podían prepararse extemporáneamente; se podía almacenar por tiempo indefinido, protegiéndose las sustancias de la luz y la oxidación; contenía la dosis exacta para administrarse una sola vez (en unidosis), siendo así más precisa y evitando una posible contaminación microbiana. Por último, su condición de esterilidad permitía que el fármaco se inyectara directamente en el torrente sanguíneo, sin sufrir los efectos adversos que producían ciertos compuestos en el aparato digestivo.

Indudablemente, la innovación tecnológica que dio un gran impulso al desarrollo de la ampolleta y de los medicamentos parenterales fue el autoclave. Se considera que el inglés Denis Papin fue el primero en construir, durante el siglo XVII, una caldera de vapor con válvula de seguridad. Sin

\footnotetext{
${ }^{3}$ Raúl Rodríguez y Antonio González, Entre el arte y la técnica. Los orígenes de la fabricación industrial del medicamento, Madrid, Consejo Superior de Investigaciones Científicas, 2005, p. 259, 260, 263.

${ }^{4}$ Stanislas Limousin, "Ampoules hypodermiques. Nouveau mode de préparation des solutions pour les injections hypodermiques”, Bulletin Général de Thérapeutique Médicale et Chirurgicale, v. 110, n. 7, 1886, p. 316-319.
} 
embargo, los principales adelantos en este equipo tuvieron lugar a finales del siglo XIX, con el auge de los productos estériles en la terapéutica. Un autoclave consistía principalmente en una caldera metálica de paredes resistentes, que se cerraba herméticamente con una tapa, en cuyo interior se colocaba un cestillo metálico con los materiales a esterilizar, un manómetro y una fuente de energía para ponerla en funcionamiento, misma que podía ser alcohol, petróleo, gas o electricidad. El fundamento principal de estos equipos era la esterilización con vapor de agua a presiones elevadas. ${ }^{5}$ Utilizado tanto en la botica como en la fábrica, el autoclave permitió la obtención de ampolletas con una esterilidad asegurada y la consecuente popularización de las formas farmacéuticas inyectables.

Para 1900, las ampolletas ya eran comúnmente utilizadas en la farmacia francesa para dispensar distintas preparaciones asépticas, como gotas oftálmicas, sueros fisiológicos, solución salina y ciertos fármacos en preparaciones líquidas. ${ }^{6}$ Los médicos franceses también las recibieron favorablemente, recetando eméticos, antianémicos, tónicos, reconstituyentes con hierro y hasta anestésicos en dichas presentaciones. El éxito de esta nueva presentación en Francia fue tan grande que la empresa Paillard-Ducatte declaró haber vendido alrededor de 8 millones de ampolletas en 1907.7 Otra compañía líder en la manufactura de ampolletas vacías era Adrain \& Fournier, ubicada en París.

En este artículo se examina la llegada de las ampolletas inyectables a diversos países europeos y americanos a finales del siglo XIX y principios del xx. Sin embargo, el propósito principal de este trabajo es analizar la introducción de las ampolletas en México y Estados Unidos, ante la escasa literatura que aborda este tema, sobre todo en la historiografía mexicana. Se trata entonces de una investigación novedosa en los campos de la historia de la ciencia, la tecnología y la farmacia. Se busca mostrar que la adopción de las ampolletas en México y Estados Unidos fue influenciada por los modelos farmacéuticos y de industrialización del medicamento que prevalecían en estas naciones, lo que dio lugar a diferencias importantes en el desarrollo y manufactura de estos productos. El periodo de estudio comienza en 1896, con el primer registro de la fabricación de ampolletas

${ }^{5}$ Rodríguez y González, Entre el arte y la técnica..., p. 265.

6 "The Paris Exposition", American Druggist and Pharmaceutical Record, 23 de julio de 1900.

7 Caswell A. Mayo, “The Ampul From the Retail Druggist's Standpoint”, American Druggist and Pharmaceutical Record, 22 de febrero de 1909. 
inyectables en Estados Unidos, y termina en 1939, con el estallido de la Segunda Guerra Mundial.

En primer lugar, este artículo hará un breve estudio del surgimiento de las ampolletas inyectables en diversos países europeos, para introducir al lector en los modelos de industrialización farmacéutica que imperaron en este continente. En segundo, se describirá el proceso general de fabricación de una ampolleta a inicios del siglo xx, con el objetivo de mostrar las variables fisicoquímicas, microbiológicas y tecnológicas que el profesional farmacéutico debía dominar para el aseguramiento de presentaciones medicinales de calidad. En tercero, se analizará con detalle la llegada de las ampolletas inyectables a los Estados Unidos y su subsecuente fabricación industrial. Finalmente, se examinará con profundidad el caso de México, buscando diferencias y similitudes entre países en la práctica farmacéutica y en los procedimientos de fabricación de la ampolleta inyectable. Sin embargo, es importante señalar que este artículo no tiene la intención de determinar cuál fue el primer país americano que fabricó localmente ampolletas inyectables.

Durante el siglo XIX, en Europa surgieron dos modelos de industrialización del medicamento, que serían determinantes para el nacimiento de la industria farmacéutica en este continente: el mediterráneo y el centroeuropeo. El modelo mediterráneo tuvo lugar en los países de la Europa del sur, como Italia, España y Francia; se basó en la elaboración de especialidades farmacéuticas sustentada en la farmacia galénica. ${ }^{8}$ El farmacéutico del mediterráneo, además de ser un experto en la formulación magistral y oficinal, dominaba las actividades de droguería, herboristería, confitería, cosmética y la elaboración de licores. ${ }^{9}$ El farmacéutico de este perfil era propenso a la elaboración individualizada y manual dentro de las reboticas de las farmacias, utilizando aparatos, instrumentos y utensilios que sólo permitían en ciertas ocasiones la producción de medicamentos a gran escala. ${ }^{10}$

El modelo centroeuropeo o anglosajón fue un producto de la Revolución Industrial y prevaleció en naciones como Suiza, Inglaterra o Alemania. Se basó en el aislamiento de alcaloides y posteriormente en la síntesis orgánica de moléculas con efecto terapéutico. Los productos medicinales se

\footnotetext{
${ }^{8}$ Francisco Javier Puerto y Antonio González, Compendio de historia de la farmacia y legislación farmacéutica, Madrid, Síntesis, 2011, p. 206-207.

${ }^{9}$ Juan Esteva de Sagrera, Historia de la farmacia: los medicamentos, la riqueza y el bienestar, Barcelona, Masson, 2005, p. 349.

${ }^{10}$ Raúl Rodríguez, Uriach, Cambronero, Gallego. Farmacia e industria. La producción de los primeros medicamentos en España, Madrid, Nivola, 2004, p. 20-22.
} 
obtenían en fábricas, en las que, además, muchas veces se elaboraba otro tipo de productos como explosivos, colorantes, perfumes o material fotográfico; es decir, en este modelo, los medicamentos eran subproductos obtenibles a partir de procesos de química industrial. La especialidad farmacéutica estaba más ligada al gran laboratorio químico que al colectivo profesional de la farmacia. Posteriormente, este modelo también se desarrolló en los Estados Unidos, debido a la influencia de la cultura inglesa sobre este país. ${ }^{11}$

El modelo centroeuropeo fue el que finalmente se impuso en gran parte del mundo, ya que significó la manufactura de medicamentos a gran escala, valiéndose de los importantes descubrimientos del siglo XIX en química y farmacología. Las principales aportaciones de este modelo fueron los comprimidos y las cápsulas de gelatina dura, que actualmente tienen un uso generalizado. Por su parte, la farmacia mediterránea no logró el mismo alcance, pues trató de acelerar y rentabilizar sus procedimientos tradicionales de elaboración manual; no obstante, esto apenas dio lugar a la mecanización de algunas de sus etapas productivas. ${ }^{12}$ Sin embargo, tuvo grandes contribuciones en cuanto a la invención de formas farmacéuticas; las cápsulas de gelatina blanda, las cápsulas amiláceas y las ampolletas inyectables surgieron de este modelo, y hoy en día las cápsulas de gelatina blanda y las ampolletas son utilizadas habitualmente.

Estas diferencias en los modelos europeos de industrialización y práctica farmacéutica fueron los principales factores que influyeron en la introducción, recepción y adopción de la ampolleta inyectable en distintas naciones. Por ejemplo, en países mediterráneos como Italia, fue bien acogida y era usada regularmente. Los médicos italianos la recetaban en casos de sífilis, tuberculosis y varias enfermedades sistémicas; los tónicos, revitalizantes y las preparaciones mercuriales también se administraban mediante esta presentación. La popularidad de la ampolleta en este país se reflejó en la Farmacopea Militar Italiana de 1893, que aumentó el número de fórmulas en donde se empleaban. Entre los comerciantes italianos de ampolletas más reconocidos, se encontraba Fratelli Bucco, que en 1909 vendía 127 tipos de ampolletas con soluciones de diversos fármacos. ${ }^{13}$

La llegada de las ampolletas inyectables a España ha sido tratada detalladamente en diversos artículos que analizan las innovaciones implemen-

11 Idem.

12 Puerto y González, Compendio de historia de la farmacia..., p. 206.

13 Caswell A. Mayo, "The Ampul from the Retail Druggist's Standpoint”, American Druggist and Pharmaceutical Record, 22 de febrero de 1909. 
tadas en este campo por los farmacéuticos locales a inicios del siglo xx. Rodríguez y González aseguran que las ampolletas fueron bien acogidas por el colectivo profesional de la farmacia española, debido a que, entre otras razones, no necesitaban de un gran desarrollo tecnológico para su elaboración; su contenido podía ser preparado de forma magistral según las necesidades del paciente y resolvían muchos problemas de la administración parenteral de soluciones medicinales. ${ }^{14}$ Los farmacéuticos españoles no se limitaron a importar estas presentaciones o a imitar los procesos desarrollados en otras latitudes, sino que también contribuyeron a su innovación y mejora. El primer artículo sobre esta materia escrito por un autor español, Emilio Alcobilla, apareció en 1903. A éste le siguieron los trabajos de diversos profesionales en las décadas siguientes, destacando los del farmacéutico militar Saturnino Cambronero, quien creó un autoclave llamado "Ideal, sistema C. G. S." y realizó avances en tubos o ampolletas empleados como testigos de esterilización y en el área de la ultrafiltración. ${ }^{15}$

En países centroeuropeos, la ampolleta inyectable se recibió con escepticismo por lo que su adopción fue lenta. A inicios del siglo xx, en Alemania y Suiza se prefería otro tipo de sistemas para la administración de productos parenterales, como la tableta hipodérmica o la solución extemporánea. Hasta 1908 empezaron a incluirse algunos métodos estandarizados en la farmacopea Suiza y en diversos artículos alemanes, que explicaban la forma de preparar y esterilizar ampolletas. La formulación de inyecciones hipodérmicas con fármacos como la cocaína, la ergotina y la morfina permitió la generalización del uso de ampolletas en la terapéutica alemana, ya que farmacéuticos y médicos reconocieron su practicidad y manejabilidad. Muchas compañías germanas se convirtieron entonces en proveedores de ampolletas tanto llenas como vacías. ${ }^{16}$

En Alemania, la fabricación de ampolletas y bulbos para sueros tuvo un gran desarrollo en la región de Turingia, siendo uno de los principales em-

${ }^{14}$ Raúl Rodríguez Nozal, "Saturnino Cambronero González (1867-1927): sus aportaciones a la sanidad y a la tecnología del inyectable”, en Juan Esteva de Sagrera y Antonio González Bueno (ed.), Cordialero de libros y medicamentos. Homenaje al Dr. José María Suñé Arbussà, Madrid, Sociedad de Docentes Universitarios de Historia de la Farmacia de España, 2009; Raúl Rodríguez Nozal y Antonio González Bueno, "Historia del medicamento industrial: la irrupción de cápsulas, comprimidos e inyectables en la farmacia española”, Industria Farmacéutica, n. 11, 2005, p. 98-104.

${ }^{15}$ Idem.

${ }^{16}$ Caswell A. Mayo, “The Ampul from the Retail Druggist's Standpoint”, American Druggist and Pharmaceutical Record, 22 de febrero de 1909. 
presarios el señor Fridolin Greiner, de Neuhaus am Rennweg, cerca de la ciudad de Jena. ${ }^{17}$ En torno de 1909, la casa alemana Merck lanzó al mercado la fibrolisina, un anticoagulante usado en el tratamiento de fibrosis crónica que era dispensado en ampolletas (protegiéndose la formulación del aire) para la vía hipodérmica. Asimismo la tropacocaína, un sustituto de la cocaína supuestamente menos tóxico, empleada para la anestesia quirúrgica u operaciones dentales, era envasada en ampolletas con $1.25 \mathrm{~cm}^{3}$ de solución. ${ }^{18}$ Otro de los medicamentos que se benefició de esto fue el famoso "compuesto 606" descubierto por Paul Ehrlich (llamado así por haber sido la molécula que curó la sífilis en conejos, luego de 605 pruebas anteriores), mejor conocido como Salvarsán y considerado como uno de los primeros fármacos quimioterapéuticos con efecto antisifilítico. En 1910, la empresa Hoechst exportaba ampolletas de Salvarsán desde Alemania a diferentes naciones. ${ }^{19}$

Vale la pena señalar que las investigaciones históricas sobre la introducción de la ampolleta inyectable en los países americanos son todavía escasas. La mayor parte de los trabajos existentes se ha enfocado en analizar el caso de los Estados Unidos, al ser uno de los primeros países de este continente donde surgió una industria farmacéutica. Algunos artículos afirman que la ampolleta tuvo un recibimiento frío por parte de los boticarios y dueños de farmacias estadounidenses, que en un inicio evitaron su fabricación al considerarla un producto poco redituable. No obstante, otras publicaciones señalan que la ampolleta inyectable sí fue aprovechada por las empresas farmacéuticas de dicho país norteamericano, y que éstas lograron desarrollar procesos rentables para su fabricación y manejo a gran escala. ${ }^{20}$

En los países de América Latina, los procesos de adopción y adaptación de las ampolletas inyectables han sido poco estudiados por los historiadores de la ciencia y la tecnología. Estos procesos merecen ser revisados porque los factores que permitieron la llegada de la ampolleta a las naciones latinoamericanas fueron diferentes a los que se presentaron en Estados Unidos, debido a las características que tenía la práctica farmacéutica en esta región del

17 "Empty Ampuls", American Druggist and Pharmaceutical Record, 27 de diciembre de 1909.

${ }^{18}$ Caswell A. Mayo, “The Ampul from the Retail Druggist's Standpoint”, American Druggist and Pharmaceutical Record, 22 de febrero de 1909.

19 "Salvarsan and Its Preparation", American Druggist and Pharmaceutical Record, 26 de diciembre de 1910.

${ }^{20}$ Fred I. Lackenbach, “Ampoules”, California State Journal of Medicine, v. 8, n. 9, 1910, p. 316-317; Caswell A. Mayo, “The Ampul from the Retail Druggist's Standpoint”, American Druggist and Pharmaceutical Record, 22 de febrero de 1909. 
mundo. A finales del siglo XIX y principios del xx, en muchos modelos farmacéuticos de países latinoamericanos había una gran influencia del modelo farmacéutico mediterráneo, que se basaba en la utilización de plantas medicinales en la confección de medicamentos y en la exclusividad de la elaboración de los mismos por los farmacéuticos dentro de sus farmacias o boticas. ${ }^{21}$

Ciertas investigaciones afirman que en México se fabricaban ampolletas inyectables desde los primeros años del siglo $\mathrm{xx}$, dentro de algunas boticas locales con el apoyo de instituciones públicas, a pesar de que no existía una industria farmacéutica nacional. Godínez y Aceves aseguran que la ampolleta fue más popular en México que en los Estados Unidos, debido a las influencias española (heredada desde la colonización) y francesa (consolidada durante el Porfiriato) sobre la farmacia mexicana de la época. Sin embargo, estos autores no discuten en su estudio los factores científicos, tecnológicos e institucionales que permitieron la comercialización y la fabricación temprana de ampolletas inyectables en este país ni sobre los personajes que estuvieron involucrados en estas iniciativas. ${ }^{22}$

Los objetivos de este artículo son describir y analizar los inicios de la fabricación de ampolletas inyectables en Estados Unidos y México. Mediante el estudio de caso de las ampolletas, se busca poner en evidencia las diferencias y similitudes en los modelos de práctica farmacéutica y de industrialización del medicamento predominantes en estas naciones a finales del siglo XIX e inicios del xx. Nuestra hipótesis es que la farmacia estadounidense, influenciada por el modelo industrializador centroeuropeo o anglosajón, inició la fabricación de ampolletas inyectables en los laboratorios de escala industrial, mientras que en la farmacia mexicana los principales actores de este proceso fueron los boticarios en sus pequeños laboratorios, lo que mostraba la influencia del modelo farmacéutico mediterráneo en este país latinoamericano.

La información presentada se obtuvo a través de investigación bibliográfica, hemerográfica, electrónica y archivística. Se consultaron las fuentes primarias constituidas por las patentes y marcas farmacéuticas registradas

${ }^{21}$ Rogelio Godínez Reséndiz y Patricia Aceves Pastrana, "La regulación del medicamento industrial en México (1926-1937)”, Revista Mexicana de Ciencias Farmacéuticas, v. 43, n. 1, 2012, p. 49-57.

${ }^{22}$ Rogelio Godínez Reséndiz y Patricia Aceves Pastrana, "El surgimiento de la industria farmacéutica en México (1917-1940)”, Revista Mexicana de Ciencias Farmacéuticas, v. 45, n. 2, 2014, p. 55-68; Rogelio Godínez Reséndiz y Patricia Aceves Pastrana, Proyectos, realidades y utopías: la transformación de la farmacia en México (1919-1940), México, Universidad Autónoma Metropolitana-Unidad Xochimilco, División de Ciencias Biológicas y de la Salud, 2014. 
en los territorios mexicano y estadounidense, por medio de las páginas electrónicas del Instituto Mexicano de la Propiedad Industrial (IMPI) y de la United States Patent and Trademark Office (USPTO), respectivamente. También se analizaron otras fuentes originales como las principales revistas científicas y de divulgación publicadas por los farmacéuticos de la época, artículos de periódicos, decretos promulgados por el gobierno mexicano y documentos provenientes del Archivo Histórico de la Secretaría de Salud (AHSSA). Finalmente, se revisó bibliografía actual para entender el estado del arte del tema abordado.

La fabricación de ampolletas inyectables a inicios del siglo $\mathrm{xx}$

Durante años, el proceso de fabricación de ampolletas inyectables se modificó conforme los avances tecnológicos alcanzados en los campos de la esterilización y la asepsia, así como en la industria del envase. La creación de nuevos instrumentos y aparatos (sobre todo de origen europeo, como el autoclave) facilitó su producción y permitió ahorrar tiempo y esfuerzo. Sin embargo, la elaboración de ampolletas tuvo peculiaridades de acuerdo con el país de origen. Aunque las variables científicas que el farmacéutico debía controlar eran las mismas, las técnicas utilizadas por un profesional francés o español podían diferir de las de su colega alemán o estadounidense.

A continuación, se describe brevemente el procedimiento general de elaboración de una ampolleta inyectable en las primeras décadas del siglo xx. Mediante el estudio de las principales variables fisicoquímicas, tecnológicas y bacteriológicas involucradas en la elaboración de estos productos, pueden identificarse diferencias y similitudes en la práctica farmacéutica de los profesionales de distintas naciones. Es importante señalar que el siguiente procedimiento se obtuvo principalmente a partir de artículos publicados por boticarios estadounidenses, por lo que podría considerarse como el método empleado en aquel país para la fabricación de ampolletas a pequeña escala. No obstante, más adelante se mostrará que este procedimiento era similar al utilizado por los farmacéuticos de otros lugares, como los mexicanos.

Desde finales del siglo xviII hasta principios del xx, los envases farmacéuticos de cristal eran fabricados por el método artesanal del vidrio soplado, que consumía mucho tiempo y además requería personal experimentado. En el periodo 1880-1910 se logró la automatización en la fabricación de botellas de vidrio de uso general para satisfacer el incremento en la demanda, 
necesitándose en adelante de una mínima intervención humana. A pesar de los avances tecnológicos, los contenedores de cristal para productos medicinales (como las ampolletas) siguieron elaborándose con vidrio soplado, debido a las pequeñas cantidades que se requerían y a los tamaños y formas especiales que se deseaban en el envase. ${ }^{23}$

Fue hasta la introducción de los tubos de cristal cuando se logró un avance significativo en esta rama. Mientras el método tradicional fundía y moldeaba el vidrio hasta su forma final, las nuevas técnicas consistían en elaborar tubos a partir del cristal fundido, para posteriormente dejarlos enfriar a temperatura ambiente. Enseguida, se volvían a calentar los tubos con flama y mediante la utilización de herramientas o instrumentos, se les daba la forma final deseada. De esta manera, pudieron producirse recipientes como viales, cartuchos, jeringas y ampolletas, entre otros. ${ }^{24}$

Hacia 1908, distintas empresas farmacéuticas ya poseían la maquinaria necesaria para fabricar ampolletas de diferentes tamaños a partir de tubos de vidrio. Las de mayor capacidad eran utilizadas para la administración continua de solución salina. Como puede observarse en la figura 1 , se fabricaban ampolletas de distintas formas, aunque se consideraba que la "forma de botella" era la más adecuada, ya que permitía que ésta permaneciera vertical mientras el médico usaba sus manos libremente para llenar la jeringa hipodérmica. En Francia se prefería la forma de tubo con los dos extremos sellados, por ser la más fácil y barata de fabricar, aunque en ésta se podían presentar ciertas dificultades en el llenado, cerrado y trasvase del líquido hacia la jeringa inyectora.

La preparación de ampolletas inyectables requería un gran cuidado por parte de los farmacéuticos. Por un lado, se tenía que emplear utensilios, instrumentos y soluciones estériles. Por el otro, debía prevenirse la contaminación microbiana en los diversos componentes de la formulación; para ello, debía contarse con una campana aséptica en el área de trabajo. Era necesario usar ampolletas de cristal neutro y evitar aquellas cuyos cristales al calentarse producían bases que reaccionaban químicamente con las soluciones y que, por lo tanto, podían causar su degradación. Esta selección de ampolletas se determinaba con una prueba de fenolftaleína, un indicador ampliamente utilizado por virar de incoloro a rosado en soluciones alcalinas.

${ }^{23}$ Schaut y Weeks, "Historical Review of Glasses...”

${ }^{24}$ Idem. 


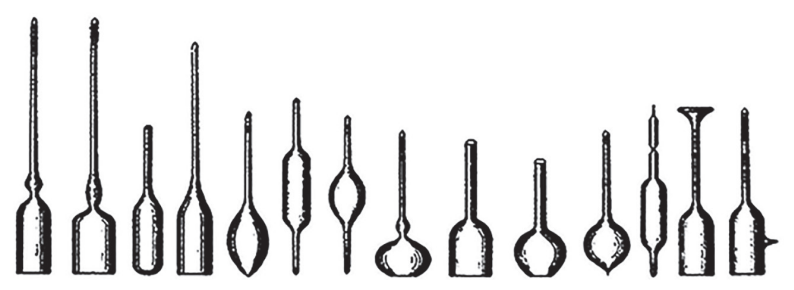

Figura 1. Formas de ampolletas a principios del siglo xx. Fuente: Caswell A. Mayo, "The Ampul and Its Uses in the Preservation of Sterile Solutions", en American Pharmaceutical Association (ed.), Proceedings of the American

Pharmaceutical Association, Baltimore, American Pharmaceutical Association, 1909, p. 1106-1117

Antes de llenar las ampolletas, debían esterilizarse las soluciones empleadas. Para esto había que tomar en cuenta varios factores. El fabricante debía poseer conocimientos químicos y bacteriológicos que implicaban conocer las propiedades de cada componente, la temperatura máxima de calentamiento de los compuestos (para evitar su degradación), las características de los solventes y el tipo de bacteria que era susceptible de crecer en cada solución preparada. Así, algunas soluciones tenían que esterilizarse en autoclave por vía seca, otras por la vía húmeda, o bien tenían que filtrarse a través de bujías de porcelana. Por último, se recomendaba realizar pruebas de control a la solución para comprobar la esterilidad, sobre todo la eliminación de bacterias esporuladas. ${ }^{25}$

La esterilización de las ampolletas vacías se realizaba por diversos métodos. Se empleaba un horno de aire caliente a una temperatura de $160^{\circ} \mathrm{C}$ a $170^{\circ} \mathrm{C}$ por dos horas, o bien un autoclave de vapor a una temperatura de $115^{\circ} \mathrm{C}$ a $120^{\circ} \mathrm{C}$ por $15-30$ minutos. Además, podía usarse la tindalización o esterilización intermitente, en la que se calentaba a $60^{\circ} \mathrm{C}$ durante media hora a intervalos de 24 horas, por tres o cuatro días consecutivos. ${ }^{26}$ Para eliminar todos los microorganismos no esporulados y algunas bacterias esporuladas, se calentaba a vapor por 30 minutos, o se hervía completamente en agua por 15 minutos, o bien se utilizaba una solución de bicarbonato de sodio (de dilución 1:1000). Por último, si se sospechaba de que los cristales

${ }^{25}$ George P. Forrester, "Some of the Difficulties in Sterilizing Ampuls", American Druggist and Pharmaceutical Record, 26 de abril de 1909.

${ }^{26}$ Hermann H. North, "Ampuls", The Journal of the American Pharmaceutical Association, v. 4 , n. 5,1915 , p. 567. 
de los recipientes utilizados contenían siquiera una mínima cantidad de bases, el proceso de esterilización debía ser precedido de una limpieza completa de la botella, la ampolleta o el recipiente con ácido clorhídrico diluido al $1 \%$, seguida de un enjuague con agua destilada. ${ }^{27}$

Para efectuar el llenado de ampolletas, los farmacéuticos desarrollaron diversas técnicas dependiendo de sus gustos personales, de su forma de trabajo y de sus necesidades productivas. Los métodos variaban desde prácticas artesanales hasta procedimientos industriales. Sin embargo, el fundamento de todos los procedimientos de llenado se basaba en el establecimiento de una diferencia de presiones tal, entre la solución medicamentosa y el interior de la ampolleta, que permitía el acomodo del fluido en el espacio anteriormente ocupado por el aire. Este diferencial podía lograrse mediante tres formas: por la acción en caída libre del líquido, por presión de éste mediante un gas o provocando un vacío en el interior de la ampolleta. ${ }^{28}$

Algunas opciones de material de vidrio para llenar ampolletas eran pipeta, bureta o una jeringa hipodérmica. El vacío dentro de la ampolleta podía generarse por calentamiento del bulbo, utilizando éter, con un autoclave o por aspiración con el aparato de Auer (este último diseñado para evitar la manipulación de los envases). En todos los procedimientos debían esterilizarse las ampolletas después de llenas, excepto con el método de Auer, donde la esterilización tenía lugar antes del llenado. ${ }^{29}$ Es importante señalar que eran los boticarios los que utilizaban con más frecuencia alguna de estas técnicas (o la combinación de ellas, formando sistemas híbridos) por su bajo costo, fácil manejo y por la obtención de lotes pequeños de inyectables.

Para la producción a gran escala, con el tiempo se desarrollaron sistemas de vacío completos y continuos, gracias al empleo de trompas de agua o de bombas de vacío accionadas por motores eléctricos, que permitían llenar un número elevado de ampolletas al mismo tiempo. Entre los más conocidos, se encontraban el modelo de Eury, el aparato de Fairchild (figura 2) o el descrito por Spindler. ${ }^{30}$ Debido a su enorme rendimiento, este tipo de

${ }^{27}$ United States Pharmacopoeial Convention, The Pharmacopoeia of the United States of America, ninth decennial revision, Philadelphia, J. B. Lippincott Company, 1916, p. 616.

${ }^{28}$ Rodríguez y González, Entre el arte y la técnica..., p. 268.

${ }^{29}$ Caswell W. Mayo, "Ampuls-Their Use in the Dispensing of Hypodermic Solutions", en American Pharmaceutical Association (ed.), Proceedings of the American Pharmaceutical Association, Baltimore, American Pharmaceutical Association, 1909.

${ }^{30}$ Caswell A. Mayo, “The Ampul from the Retail Druggist's Standpoint”, American Druggist and Pharmaceutical Record, 22 de febrero de 1909. 


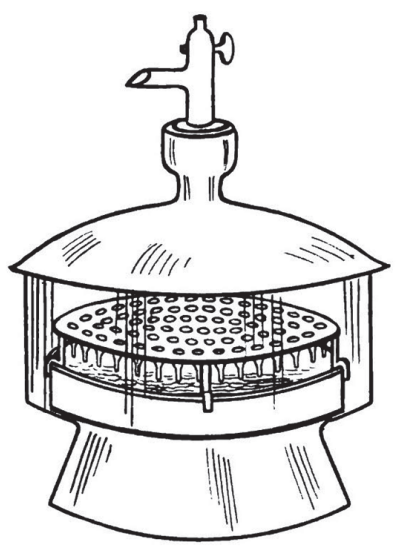

Figura 2. Aparato de Fairchild para llenar ampolletas por vacío. Fuente: Mayo, “The Ampul and Its Uses..."

equipos era el más empleado en las grandes compañías farmacéuticas; sin embargo, gozaban de poca aceptación entre los dueños de farmacias, ya que su precio era demasiado elevado y el llenado sólo podía ser rentable a escalas industriales.

Las ampolletas se cerraban sometiendo sus cuellos a la acción de una llama calorífica suficientemente potente como para conseguir el corte y fusión del vidrio. El instrumento más apropiado para el cierre era un soplete accionado por gas y aire comprimido que producía una flama de gran potencia para el sellado uniforme y seguro. Una vez cerradas y esterilizadas, las ampolletas se sometían a una prueba de hermeticidad, sumergiéndolas en una solución colorante para determinar si había fuga. Las que pasaban esta prueba se lavaban, limpiaban, secaban y se revisaban a contraluz, desechando aquellas que tuvieran fibras, partículas de vidrio o algún corpúsculo en su interior. ${ }^{31}$

Diversas ampolletas eran fabricadas con una muesca en el vidrio para facilitar su rompimiento, aunque esta característica frecuentemente provocaba que sufrieran fracturas o grietas. Entonces, los fabricantes comenzaron a vender ampolletas sin muesca, pero incluían una pequeña cuchilla de metal para facilitar su apertura. ${ }^{32}$ El etiquetado final dependía en gran medida del fabricante: los franceses no acostumbraban colocar etiquetas sobre

${ }^{31}$ Rodríguez y González, Entre el arte y la técnica..., p. 275-278.

32 Caswell A. Mayo, “The Ampul from the Retail Druggist's Standpoint”, American Druggist and Pharmaceutical Record, 22 de febrero de 1909. 
la ampolleta misma, sino en el envase secundario (aquel que envolvía a la ampolleta), mientras que los alemanes y estadounidenses sí etiquetaban el vidrio de la ampolleta. Como paso final del proceso productivo, se acondicionaban los productos en cajas de cartón.

Con el paso de los años se llevaron a cabo investigaciones para elaborar cristales cada vez más resistentes, químicamente durables y con las propiedades ópticas adecuadas. En un inicio, los cristales que se utilizaban para la fabricación de ampolletas eran del tipo soda-lime (con una durabilidad pobre), obtenidos a partir de componentes baratos y fácilmente disponibles como arena, piedra caliza y carbonato de sodio. Hacia 1910, empezaron a fabricarse ampolletas de cristal borosilicato para almacenar soluciones parenterales, observándose un desempeño superior. Poco después, en 1911, la compañía alemana Jena Laboratories introdujo un cristal para ampolletas llamado alpha-glass, normal 16 III, también conocido como fiolax glass, que se convertiría en el material habitual para estas presentaciones. ${ }^{33}$

\section{El desarrollo de ampolletas inyectables en los Estados Unidos}

A finales del siglo xix, en Estados Unidos ya existía una industria farmacéutica sólida en pleno crecimiento. Distintas empresas locales destinaban recursos en rubros como la investigación científico-tecnológica y, por consecuencia, los descubrimientos realizados en disciplinas como bacteriología, farmacología y química orgánica permitieron el diseño de nuevos medicamentos en este país. Entre las compañías líderes en investigación se encontraban H. K. Mulford Company de Filadelfia y Lederle Laboratories de Nueva York, que establecieron laboratorios para elaborar productos biológicos como antitoxina diftérica, vacunas antirrábicas, antitoxina tetánica o el suero antiestreptocócico. ${ }^{34}$ Ambas firmas comenzaron a emplear diversos tipos de envases para contener dichas preparaciones, sobre todo viales de cristal transparente o ámbar.

${ }^{33}$ Schaut y Weeks, "Historical Review of Glasses Used..."

${ }^{34}$ John P. Swann, "The Evolution of the American Pharmaceutical Industry", Pharmacy in History, 37-2, 1995, p. 76-86; Jonathan M. Liebenau, "Scientific Ambitions. The Pharmaceutical Industry, 1900-1920”, Pharmacy in History, v. 27, n. 1, 1985, p. 3-11; Maurice L. Tainter y G. M. A. Marcelli, "The Rise of Synthetic Drugs in the American Pharmaceutical Industry", Bulletin of the New York Academy of Medicine, v. 35, n. 6, 1959, p. 387-405. 
Sin embargo, en el periódico American Druggist and Pharmaceutical Record (publicado por farmacéuticos estadounidenses y uno de los más importantes de la época) se leían artículos sobre productos medicinales que se comercializaban en Estados Unidos, algunos de los cuales estaban envasados en "bulbos de cristal". ${ }^{35}$ En 1896, una de las compañías farmacéuticas más importantes, Parke, Davis \& Company, de la ciudad de Detroit, utilizaba bulbos de cristal herméticamente sellados y asépticos para el envase de los sueros antidiftérico, antiestreptocócico y antitetánico; y en fármacos como la ergotina (un estimulante muscular uterino, espasmódico y hemostático). Estos bulbos eran fabricados en el Departamento Biológico que esta empresa tenía en el estado de Michigan. ${ }^{36}$

Se puede asegurar que los bulbos de cristal que empleaba Parke, Davis \& Company en los últimos años del siglo decimonónico eran precisamente ampolletas, debido a que poseían las mismas características que estas últimas. Dichos bulbos eran estériles, cerrados herméticamente, fabricados con el mismo material, fáciles de manipular, almacenaban la formulación indefinidamente y la protegían de contaminaciones microbianas y de posibles degradaciones; eran unidosis y para su administración en el paciente se debía trasvasar el líquido a una jeringa hipodérmica. Probablemente, el concepto europeo de "ampolleta" era todavía extraño para los fabricantes estadounidenses, por lo que llamaban "bulbos" a las mismas presentaciones. Así, la introducción de estos bulbos de cristal hacia 1896 por Parke, Davis \& Company para el envase de sueros, antitoxinas y vacunas, marca el inicio de la fabricación local de ampolletas inyectables en los Estados Unidos. ${ }^{37}$

Durante los años siguientes, en el mercado estadounidense continuaron apareciendo productos parenterales nacionales e importados en forma de bulbos de cristal, fabricados principalmente por compañías farmacéuticas. Además, el desempeño superior de estos bulbos en la protección de fármacos sensibles se hizo patente en la edición de 1900 de la United States Pharmacopeia (USP). De acuerdo con este documento, el nitrito de amilo $\left(\mathrm{C}_{5} \mathrm{H}_{11} \mathrm{NO}_{2}\right)$, un compuesto usado para la epilepsia, histerismo, jaqueca, lipotimias y anede 1891.

35 "An Interesting Window", American Druggist and Pharmaceutical Record, 1 de mayo

${ }^{36}$ Parke, Davis \& Company, “Anti-Diphtheritic Serum”, Therapeutic Notes, junio de 1896; Parke, Davis \& Company, Physician's Manual of Therapeutics: Referring Especially to the Products of the Pharmaceutical and Biological Laboratories of Parke, Davis \& Company, Detroit, Parke, Davis \& Company, 1901, p. 80, 220.

${ }^{37}$ Parke, Davis \& Company, “Anti-Diphtheritic Serum”, Therapeutic Notes, junio de 1896. 
mia cerebral, debía envasarse en viales de color ámbar oscuro, en bulbos de cristal herméticamente sellados o en lugares frescos y oscuros. ${ }^{38}$

A pesar de sus ventajas, a inicios del siglo $\mathrm{xx}$, los bulbos de cristal o ampolletas inyectables no eran populares en los Estados Unidos. De igual forma, entre las grandes empresas norteamericanas, Parke, Davis \& Company era posiblemente la que más apostaba a estos productos, dado que para 1908 ya fabricaba ampolletas de vidrio a gran escala en su planta de Detroit. De acuerdo con una visita realizada a esta fábrica por un miembro de la Sociedad Científica Mexicana "Antonio Alzate", las instalaciones comprendían salones donde numerosas mujeres trabajaban con su soplete las ampolletas que contenían soluciones inyectables o cerraban a la lámpara (mechero bunsen) los tubos de vidrio manufacturados. ${ }^{39}$

Entre las principales causas por las cuales la ampolleta inyectable no era popular en los Estados Unidos, se encontraba la desconfianza hacia ésta por parte de los boticarios y dueños de farmacias. Al igual que en los países centroeuropeos, los farmacéuticos estadounidenses preferían el empleo de otras formas farmacéuticas para inyectables, como las tabletas hipodérmicas, preparando sus soluciones de forma extemporánea cada vez que las necesitaran. Para algunos boticarios, la fabricación de ampolletas en las farmacias era complicada por los cuidados que se requerían, en especial los relacionados con la esterilización. Además, una de las objeciones que se hacían a la ampolleta era el peligro de introducir pequeñas astillas de vidrio en el tejido si ésta no se rompía adecuadamente, aunque también se reconocía que este inconveniente se había presentado en muy pocos casos. ${ }^{40}$

Otros boticarios la veían como una especialidad farmacéutica que no dejaba ganancias, dado que en el mercado estadounidense podían encontrarse presentaciones industriales de ampolletas llenas y estériles (sobre todo de origen europeo) a un precio menor de lo que costaría fabricarlas dentro de una farmacia (que involucraba operaciones como el moldeo, llenado y esterilización), por lo que no resultaba rentable para el pequeño

${ }^{38}$ United States Pharmacopoeial Convention, The Pharmacopoeia of the United States of America, eighth decennial revision, Philadelphia, J. B. Lippincott Company, 1905, p. 45.

${ }^{39}$ Eduardo Armendaris, "Una visita a la Casa de Parke y Davis, en Detroit, Mich., E. U. A.”, en R. Aguilar y Santillán (ed.), Memorias de la Sociedad Científica "Antonio Alzate”, México, Imprenta del Gobierno Federal, 1908, p. 29-35.

${ }^{40}$ Caswell A. Mayo, “The Ampul from the Retail Druggist's Standpoint”, American Druggist and Pharmaceutical Record, 22 de febrero de 1909. 
comerciante elaborar productos de este tipo a partir de fórmulas magistrales u oficinales. ${ }^{41}$ De igual forma, tampoco gozaban de una reputación buena entre los médicos. En 1909, el farmacéutico estadounidense Caswell A. Mayo, oriundo de Nueva York y miembro de diversos colegios de farmacia, dudaba de que la ampolleta llegara a ser apreciada alguna vez entre el gremio médico de ese país, afirmando que:

El médico estadounidense [...] ha sido entrenado para escribir prescripciones, y es muy adverso a administrar personalmente los medicamentos [...] Los médicos estadounidenses no comprarán ni usarán algo en forma de medicamento que involucre algún esfuerzo físico mayor al de escribir prescripciones, y por esta razón la ampolleta nunca será popular. ${ }^{42}$

Sin embargo, el hecho de que las ampolletas inyectables fueran productos redituables en las boticas europeas atrajo lentamente la atención de los farmacéuticos estadounidenses. De igual forma, los médicos que se formaban en universidades de Europa regresaban a los Estados Unidos ya familiarizados con la ampolleta y comenzaron a solicitarla en los hospitales. Pese a sus críticas, Mayo aseguraba que "aunque no hubiera dinero en ello", el profesional de la farmacia debía conocer el proceso manual de preparación de ampolletas para usarlas en caso de emergencias o para enfrentar situaciones especiales, dado que muchos médicos seguían recetando productos magistrales y deseaban que existieran boticarios que les prepararan soluciones inyectables de acuerdo con sus propias fórmulas. ${ }^{43}$

A pesar del recibimiento frío en las farmacias, las compañías norteamericanas aumentaron considerablemente su interés hacia las ampolletas inyectables. En 1908, la empresa Kny-Scheerer Company, de Nueva York, comenzó a importar ampolletas tanto vacías como llenas a los Estados Unidos, bajo la marca "Ariston Ampulla", mismas que fueron bien recibidas por la profesión médica. También las compañías H. K. Mulford Company y Fougera \& Company incursionaron en la venta de esta clase de productos. ${ }^{44}$

${ }^{41}$ Caswell A. Mayo, "Ampuls and Their Use in the Dispensing of Hypodermic Solutions", American Druggist and Pharmaceutical Record, 28 de diciembre de 1908.

${ }^{42}$ Caswell A. Mayo, “The Ampul from the Retail Druggist's Standpoint”, American Druggist and Pharmaceutical Record, 22 de febrero de 1909.

${ }^{43}$ Caswell A. Mayo, "Ampuls and Their Use in the Dispensing of Hypodermic Solutions", American Druggist and Pharmaceutical Record, 22 de febrero de 1909.

${ }^{44}$ Idem. 
Parke-Davis lanzó al mercado una serie de medicamentos en presentación de ampolleta, como una solución de adrenalina, la "codrenina" (una combinación de adrenalina y cocaína empleada como anestésico local y antihemorrágico), la "eudrenina" (otro anestésico local compuesto por adrenalina y beta-eucaína) y el cloroformo para inhalación. ${ }^{45}$

La compañía neoyorquina Fairchild Brothers \& Foster vendía presentaciones de secreciones animales como tripsina y amilopsina en cajas de 12 ampolletas. La empresa francesa Chevretin et Lematte estableció una sucursal en Detroit para comercializar especialidades en forma de ampolletas como el suero "neuro-tonique", hecho de agua de mar (una novedad terapéutica de la época), cacodilato y glicerofosfato de estricnina. En suelo estadounidense, la casa inglesa Burroughs, Wellcome \& Company vendía una ampolleta con una base en forma de jarrón llamada "vaporula" y la empresa Martindale, de Londres, comercializaba ampolletas llenas con el nombre de "sterules". La compañía norteamericana Lehn \& Fink puso a la venta una línea de soluciones que eran populares en los Estados Unidos para inyecciones hipodérmicas. ${ }^{46}$ En 1909, diversos productos franceses en forma de ampolletas fueron introducidos en el mercado estadounidense con un éxito moderado. En los años siguientes, comenzaron a establecerse en este país importadoras alemanas e italianas de ampolletas, principalmente en la ciudad de Nueva York. ${ }^{47}$

Debido al incremento en la preparación de soluciones inyectables para las vías hipodérmica e intravenosa, diversos farmacéuticos comenzaron a exigir a los miembros de la Convención de la usp que se estandarizara un método para la elaboración de estos productos, que cumplieran ambos fabricantes: la industria farmacéutica y los dueños de farmacias. En la usP de 1910 se incluyó por primera vez un capítulo dedicado a la esterilización de soluciones y recipientes. En el apartado de utensilios de metal y cristal,

${ }^{45}$ Parke, Davis \& Company, Catalogue of the products of the Laboratories of Parke, Davis \& Company, London, Parke, Davis \& Company, 1907-1908, p. 169, 175, 178; Parke, Davis \& Company, Manual of Therapeutics: Referring Especially to the Products of the Pharmaceutical and Biological Laboratories of Parke, Davis \& Company, Detroit, Parke, Davis \& Company, 1909, p. 93.

${ }^{46}$ Caswell W. Mayo, “The Ampul and Its Uses in the Preservation of Sterile Solutions", en American Pharmaceutical Association (ed.), Proceedings of the American Pharmaceutical Association, Baltimore, American Pharmaceutical Association, 1909, p. 1106-1117.

${ }^{47}$ Caswell A. Mayo, “The Ampul from the Retail Druggist's Standpoint”, American Druggist and Pharmaceutical Record, 22 de febrero de 1909; F. W. Nitardy, "Practical Pharmacy Methods and Devices", The Journal of the American Pharmaceutical Association, v. 2, n. 3, 1913, p. 314-324. 
se mencionaba finalmente el término "ampolleta" (en inglés, ampul). ${ }^{48}$ Años después, The National Formulary de 1916, elaborado por la American Pharmaceutical Association (Asociación Farmacéutica de los Estados Unidos), presentó un capítulo más detallado sobre esterilización. ${ }^{49}$

El despegue de las ampolletas inyectables en los Estados Unidos ocurrió con la entrada de este país a la Primera Guerra Mundial (1914-1918). Ante la imposibilidad de preparar soluciones estériles extemporáneas en el campo de batalla, el uso de ampolletas para medicamentos y vacunas parenterales permitió superar diversas dificultades médicas dentro del ejército norteamericano. De este modo, la ampolleta inyectable empezó a ganar ventaja sobre otros sistemas farmacéuticos de dosificación, como la tableta hipodérmica. No obstante, la ampolleta no era el único envase disponible para sustancias inyectables. En el caso de las vacunas, eran ampliamente utilizadas las botellas de vidrio con tapón de caucho, ya que permitían emplear pequeñas cantidades a partir de un volumen grande de solución, sin desechar lo restante y conservando la esterilidad del producto. ${ }^{50}$

Durante los años veinte y treinta del siglo $\mathrm{xx}$, diversas patentes sobre ampolletas inyectables fueron concedidas en los Estados Unidos. Muchas de las invenciones consistían en fusionar las ampolletas con jeringas hipodérmicas, facilitándose la administración de líquidos. En 1924, el inventor George N. Hein, de San Francisco, California, registró la patente de una jeringa hipodérmica cuyo pistón podía ser una ampolleta o un vial. ${ }^{51}$ Asimismo, en 1926, le fue concedida la patente a Henry Kinsey Brown, de Chicago, Illinois, sobre una ampolleta tubular que era introducida dentro de una jeringa de la misma forma. ${ }^{52}$ También se concedió protección industrial a diversas mejoras en el diseño de estos sistemas, como se ob-

${ }^{48}$ United States Pharmacopoeial Convention, The Pharmacopoeia of the United States..., p. 616.

${ }^{49}$ American Pharmaceutical Association, The National Formulary, 4a. ed., Philadelphia, J. B. Lippincott Company, 1919, p. 27.

${ }^{50}$ F. W. Nitardy, "Profit and Professional Advantages of Pharmaceutical Manufacturing by the Retail Pharmacist", The Journal of the American Pharmaceutical Association, v. 4, n. 7, 1915, p. 804-813.

${ }^{51}$ United States Patent Trademark Office (en adelante, usPTo), patente 1563627, fecha de aplicación: 23 de diciembre de 1924; fecha de concesión: 1 de diciembre de 1925.

${ }^{52}$ USPTO, patente 1594493, fecha de aplicación: 16 de septiembre de 1922; fecha de concesión: 3 de agosto de 1926. 
serva en las patentes otorgadas en 1929 a Stuart Kabnick ${ }^{53}$ de Filadelfia, Pennsylvania, y en 1933 a William O. Vopata, de Oak Park, Illinois, sobre ampolletas con diversos compartimentos donde se mantenía a los fármacos por separado. ${ }^{54}$ De igual manera, comenzaron a perfeccionarse los procesos mecánicos involucrados en su fabricación. En 1934, fue otorgada una patente al inventor estadounidense Fred C. de Lano, de South Pasadena, California, sobre un aparato para sellar ampolletas en serie, ${ }^{55}$ y en 1939 , se concedió la patente a Frank Cozzoli, de Plainfield, Nueva Jersey, de un dispositivo para llenar ampolletas con precisión, de manera total o fraccionada, en un número determinado de unidades. ${ }^{56}$

A pesar del escalamiento rápido en la producción de ampolletas, la industria farmacéutica estadounidense no consiguió liderar el mercado de inyectables en los demás países americanos. Antes de la Segunda Guerra Mundial (1939-1945), los medicamentos europeos, sobre todo de origen alemán, predominaban en las farmacias latinoamericanas. En muchas naciones de América Latina los productos inyectables ya se fabricaban localmente, si bien a base de materias primas y maquinaria extranjera. Por ejemplo, en 1939, la mayoría de los medicamentos que se vendían en México provenían de Alemania. De los $\$ 26289605.00$ pesos mexicanos a que ascendía el valor total de los productos farmacéuticos importados a finales de ese año, la mayoría eran de origen teutón con $\$ 10825436.00$; seguía la importación derivada de Estados Unidos con $\$ 6442$ 037.00. En tercer lugar, figuraban las importaciones procedentes de Francia con un valor de $\$ 5246143.00$; y en cuarto lugar las de procedencia suiza, que fueron de $\$ 1150938.00 .{ }^{57}$

Sería con la aparición de los antibióticos durante las décadas de los cuarenta y cincuenta que la industria farmacéutica estadounidense se convirtió en la líder mundial. En estos años, las empresas norteamericanas innovaron a un ritmo acelerado las técnicas de producción de estos compuestos, adueñándose de su comercialización y distribución alrededor del

${ }^{53}$ USPTO, patente 1727987, fecha de aplicación: 13 de marzo de 1929; fecha de concesión: 10 de septiembre de 1929.

${ }^{54}$ USPTO, patente 1929616, fecha de aplicación: 29 de abril de 1932; fecha de concesión: 10 de octubre de 1933.

${ }^{55}$ usPTo, patente 1967766, fecha de aplicación: 1 de junio de 1931; fecha de concesión: 24 de julio de 1934.

${ }^{56}$ USPTO, patente 2150760, fecha de aplicación: 28 de enero de 1938; fecha de concesión: 14 de marzo de 1939.

${ }^{57}$ E. Uribe Romo, "Nuevas perspectivas en el comercio internacional de medicinas a causa de la guerra”, Revista de Economía, v. 1, n. 8, 1940, p. 37. 
mundo. Las ampolletas estériles se convirtieron entonces en los envases predilectos para las formulaciones con antibióticos, ya que muchos de ellos se administraban por vías parenterales. El dominio estadounidense en este campo fue tan avasallador, que sólo las industrias inglesa y suiza pudieron competir en cierto grado. Las compañías farmacéuticas alemanas, afectadas gravemente por la guerra (la mayoría fueron confiscadas), se recuperarían hasta finales de los años cincuenta. ${ }^{58}$

Llegada de las ampolletas inyectables a México

A finales del siglo Xıx, las formas farmacéuticas más comunes utilizadas en México para dosificar adecuadamente los principios activos eran: extractos, tinturas, jarabes, polvos, granulados, tabletas, sinapismos, gelatinas, ungüentos, pomadas, perlas, cápsulas, grageas azucaradas y píldoras. ${ }^{59}$ Sin embargo, el desarrollo de la esterilización y la asepsia en Europa, así como el empleo de envases de cristal para el almacenamiento de productos parenterales, comenzaron a ser temas de discusión entre los farmacéuticos de este país. Rodríguez afirma que los científicos mexicanos estaban al tanto de los avances realizados en el viejo continente en el campo de la terapéutica y señala que durante el periodo histórico del Porfiriato (1876-1911), la ciencia francesa influyó enormemente en la medicina y la farmacia nacionales. ${ }^{60}$ De esta forma, el surgimiento de nuevas técnicas y formas farmacéuticas en países como Francia no pasó inadvertido para los profesionales mexicanos.

Las farmacopeas mexicanas de 1896 y 1904 muestran que los farmacéuticos locales ya conocían diversas técnicas de esterilización y asepsia, las cuales utilizaban para la preparación de líquidos inyectables destinados a administrarse principalmente por vía subcutánea o hipodérmica. ${ }^{61}$ De

${ }^{58}$ Rogelio Godínez Reséndiz, Patricia Aceves Pastrana, Juan Manuel Corona Alcántar y Nicolás Cárdenas García, "Introducción de los antibióticos en México: investigación científica y producción industrial (1944-1955)”, Llull, Revista de la Sociedad Española de Historia de las Ciencias y de las Técnicas, v. 39, n. 83, 2016, p. 103-133.

${ }^{59}$ Mariana Ortiz Reynoso, Martha Díaz Flores, Hariz Islas Flores, Liliana Schifter Aceves, “Técnicas e instrumentos químico-farmacéuticos en México (1849-1925)", Ciencia Ergo-Sum, v. 24, n. 1, 2017, p. 54-64.

${ }^{60}$ Ana Cecilia Rodríguez de Romo, "La ciencia pasteuriana a través de la vacuna antirrábica: el caso mexicano”, Dynamis, n. 16, 1996, p. 291-316.

${ }^{61}$ Sociedad Farmacéutica Mexicana, Nueva farmacopea mexicana de la Sociedad Farmacéutica Mexicana, México, Oficina Tipográfica de la Secretaría de Fomento, 1896; Sociedad 
igual forma, la comunidad médica también estaba interesada en la fabricación y envase de sueros artificiales. En 1898, en una reunión de la Academia de Medicina, se propuso el almacenamiento de suero en una ampolleta de gran tamaño que podía contener 300 gramos de líquido, con un extremo libre conectado a una jeringa. Con esto, se buscaba facilitar la administración intrahospitalaria de medicamentos y reemplazar los matraces de cristal utilizados como envases habituales para estas preparaciones. Aunque se construyeron prototipos de esta ampolleta, a la que se llamó frasco-pipeta, algunos médicos aseguraban que su elaboración era costosa y además debía perfeccionarse para después generalizar su empleo. ${ }^{62}$

El creciente interés de los farmacéuticos mexicanos por la esterilización y la ampolleta inyectable puede leerse en diversos artículos de la revista $L a$ Farmacia. Desde 1884, esta publicación fungía como el órgano comunicativo oficial de la Sociedad Farmacéutica Mexicana (SFM), reconocida como la agrupación farmacéutica más influyente de la época. Durante décadas, La Farmacia representó el principal medio por el cual los profesionales farmacéuticos dieron a conocer sus investigaciones y discutían los problemas propios de su gremio. Por ejemplo, en un artículo de 1901, el farmacéutico mexicano Federico F. Villaseñor ya manifestaba la importancia de preparar adecuadamente soluciones como el suero fisiológico artificial, utilizando ampolletas de 250 centímetros cúbicos de capacidad, con irrigador y cánula incluidos. ${ }^{63}$ También se transcribían en la revista distintos artículos de científicos extranjeros para difundir los últimos avances en el campo de la farmacia, como el del italiano E. Baroni de 1902, dedicado a la preparación del clorhidrato de morfina para uso hipodérmico en ampolletas de vidrio neutro. ${ }^{64}$

Por otra parte, se tiene conocimiento de que en el Instituto Patológico Nacional, las vacunas y sueros producidos eran almacenados en envases estériles de cristal. En 1903, la Sección de Bacteriología de esta institución fabricaba las vacunas de Haffkine y Besredka, utilizadas para la inmunización contra la peste bubónica que se había propagado ese año en puertos como Mazatlán, Sinaloa. En una primera instancia, estas vacunas eran envasadas

Farmacéutica Mexicana, Nueva farmacopea mexicana de la Sociedad Farmacéutica Mexicana, México, Oficina Tipográfica de la Secretaría de Fomento, 1904.

62 "El suero artificial”, El Tiempo, 18 de noviembre de 1898.

${ }^{63}$ Federico F. Villaseñor, “Algunas consideraciones acerca del suero fisiológico artificial”, La Farmacia, v. 10, n. 3, 1901, p. 73-87.

${ }^{64}$ E. Baroni, “El clorhidrato de morfina para uso hipodérmico”, La Farmacia, v. 11, n. 3, 15 de marzo de 1902, p. 55-59. 
en frascos estériles de vidrio cerrados con tapones de corcho parafinado. Sin embargo, esta clase de envase provocaba que los productos se contaminaran antes de llegar a su destino, por lo que los científicos de este instituto (compuesto en su mayoría por médicos) decidieron utilizar un proceso diferente de acondicionamiento. Así, en lo sucesivo las vacunas fueron envasadas en tubos de ensayo, previamente esterilizados y de gran tamaño, que después se cerraban con mechero y se volvían a esterilizar a $70^{\circ} \mathrm{C}$ por una hora. Estos envases eran multidosis, es decir, cada tubo elaborado permitía vacunar a 11 personas. Asimismo, de acuerdo con los reportes de la Sección de Bacteriología, el envasado en tubos se mejoró con el tiempo, dado que en un inicio se tuvieron problemas para lograr el cierre hermético. ${ }^{65}$

Creemos que los tubos de ensayo que se utilizaban en el Instituto Patológico no pueden considerarse ampolletas, ya que uno de los principales requisitos que deben cumplir estas últimas es la unidosis, como lo señalaban diversos artículos farmacéuticos de la época. ${ }^{66}$ De igual forma, se conocen pocos detalles sobre esta técnica de envasado en tubos. Seguramente, los médicos del Instituto conocían las ampolletas de una sola dosis; sin embargo, es probable que no las usaran al necesitar en mayor medida recipientes multidosis que redujeran los tiempos y costos de fabricación y que permitieran la vacunación simultánea de un gran número de personas. No obstante, esto demuestra que los científicos mexicanos conocían las ventajas de los envases estériles y herméticos de cristal, como alargar el tiempo de vida de los productos biológicos. ${ }^{67}$

Los boticarios mexicanos reconocían que la esterilización era un proceso delicado, difícil y que requería de paciencia, razón por la cual consideraban que los productos estériles debían ser tratados como medicamentos de

65 "Sección de Bacteriología. Departamento de Vacunas y Sueros", Boletín del Instituto Patológico, 2a. época, t. 1, octubre de 1903, p. 380-382; "Sesión del 11 de septiembre de 1903", Boletín del Instituto Patológico, 2a. época, t. 1, enero de 1904, p. 516-519; José P. Gayón, "Las vacunas antipestosas de Haffkine y Besredka”, Boletín del Instituto Patológico, 2a. época, t. 3, n. 8, octubre de 1905 .

${ }^{66}$ Parke, Davis \& Company, "Quick-Acting, Reliable, and Aseptic Ergot - a fine preparation", Therapeutic Notes, septiembre de 1898; Parke, Davis \& Company; “Gleanings”, Therapeutic Notes, noviembre de 1897; Parke, Davis \& Company, "Diphtheria, and Antidiphtheritic Serum as a Specific”, Therapeutic Notes, febrero de 1903.

${ }^{67} \mathrm{Al}$ parecer, estos tubos cerrados también se empleaban en algunas boticas para envasar productos. En 1894, la botica de la calle de Ortega vendía líquidos orgánicos inyectables extraídos de diferentes órganos del cuerpo humano, envasados en tubos estériles cerrados a la lámpara y preparados por el doctor Nicolás Ramírez de Arellano y el profesor Fernando Luna. “Líquidos orgánicos inyectables”, El Tiempo, 14 de enero de 1894. 
tipo oficinal y no magistral (es decir, tenían que elaborarse siguiendo indicaciones de la farmacopea vigente y no a partir de recetas médicas). Sin embargo, la SFM, quien era la responsable de redactar y actualizar las farmacopeas, no incluyó en las ediciones de la Farmacopea Mexicana de 1896 y 1904 un apartado dedicado a estandarizar los procesos de esterilización, sino que estas versiones exponían de manera individual cada una de las técnicas necesarias. De igual forma, ambos textos señalan que los inyectables debían almacenarse en frascos de vidrio esmerilados y estériles, pero no explican los criterios para seleccionar y preparar estos envases.

Las primeras noticias que se tienen sobre la fabricación perfeccionada y el uso intensivo de la ampolleta inyectable en territorio mexicano, específicamente en la ciudad de México, se encuentran en un artículo publicado en La Farmacia. Hacia 1904, en la Botica del Hospital de Jesús, ubicada cerca del zócalo principal de la ciudad ${ }^{68}$ los alumnos de la carrera de Farmacia realizaban sus prácticas profesionales y aprendían los conocimientos teórico-prácticos necesarios para la fabricación de medicamentos en general y de los inyectables estériles en particular. Esta botica era propiedad del profesor Juan B. Calderón, un prestigioso farmacéutico, profesor de la Escuela Nacional de Medicina (ENM) y miembro de la SFM. Además, este establecimiento funcionaba como sede de la secretaría de la SFM. De acuerdo con los anuncios comerciales publicados en La Farmacia, la Botica del Hospital de Jesús vendía sueros estériles, como el de Hayem, Trunecek, Cheron y el fisiológico, al igual que inyecciones hipodérmicas, pastillas medicinales, gránulos y mentol salil, entre otras presentaciones. ${ }^{69}$

El método que seguían los farmacéuticos para preparar medicamentos inyectables en esta botica era el siguiente: primero, se esterilizaban pequeños matraces Erlenmeyer en una estufa seca a $120^{\circ} \mathrm{C}$ por 40 minutos. Una vez fríos los matraces, se vertía el solvente; si era agua, debía estar destilada y hervida, y en caso de usar aceite, éste tenía que estar previamente esterilizado. Después, el principio activo se disolvía por agitación, o en su caso, empleando el calor (si éste no causaba degradaciones). Si el fármaco era muy soluble, se colocaba dentro de una bujía de filtración para que al paso del solvente se disolviera; una vez filtrada la solución, se recogía en un envase apropiado y estéril. Si el fármaco era insoluble, se sometía a una porfirización o pulverización fina, esterilizándose después a la lámpara y

${ }^{68}$ En 1917, la dirección de la Botica del Hospital de Jesús era avenida Pino Suárez 35.

${ }^{69}$ Manuel Urbina, “Trabajo inaugural”, La Farmacia, v. 13, n. 11, 1904, p. 225-233. 
con autoclave en pequeños tubos de cristal cerrados. Posteriormente, el fármaco se mezclaba con los solventes estériles dentro de un aparato donde pudiera agitarse fuertemente. ${ }^{70}$

Las técnicas de esterilización no diferían en mucho a las del resto del mundo y se usaban principalmente tres: a) esterilización por medio de calor; b) esterilización por tindalización; y c) esterilización por filtración. La esterilización por calor se llevaba a cabo en un autoclave o estufa, a una temperatura de $110^{\circ} \mathrm{C} \mathrm{a} 120^{\circ} \mathrm{C}$, siendo el procedimiento más rápido y seguro para aquellas sustancias no degradables, así como para todo tipo de utensilios y envases. La tindalización era similar a la practicada en Estados Unidos o Europa. En ésta, se sometían los líquidos a una temperatura de $58^{\circ} \mathrm{C}-60^{\circ} \mathrm{C}$ durante una hora, para después descender hasta $37^{\circ} \mathrm{C}$. Este procedimiento se repetía tres veces a intervalos de 24 horas, eliminando así los microorganismos de tipo esporulado; para este método podía utilizarse simplemente una estufa de calor seco. Finalmente, la esterilización por filtración se realizaba por vacío mediante un aparato sencillo y económico. La figura 3 muestra este dispositivo para filtrar que consistía en un embudo esférico de separación (A) que llevaba un tapón de algodón aséptico (B). La otra extremidad del embudo comunicaba con una bujía (C) que entraba dentro de un matraz (D), con un tubo ensamblado (F) para hacer el vacío y otro tubo $(G)$ que servía para vaciar el contenido. ${ }^{71}$

El dispositivo que se utilizaba en la Botica del Hospital de Jesús para llenar ampolletas se muestra en la figura 4 y fue diseñado por Ricardo Caturegli, otro célebre farmacéutico mexicano también miembro de la SFM. Se trataba principalmente de un aparato que utilizaba la gravedad como mecanismo de llenado. Se componía de un recipiente (A) que llevaba adaptado un tubo de caucho (B) de 20 centímetros, con una llave de cristal al final. A esta llave estaba conectado otro tubo de caucho para tomar allí por presión la ampolleta. Para usar el dispositivo, primero se llenaba el recipiente con el líquido a utilizar (previamente esterilizado), se colocaba la ampolleta en el tubo de caucho terminal, se abría la llave dejando llegar el líquido hasta la ampolleta, llenándose ésta hasta el volumen deseado; después se cortaba el flujo con la llave y por medio de una lámpara se cerraban 


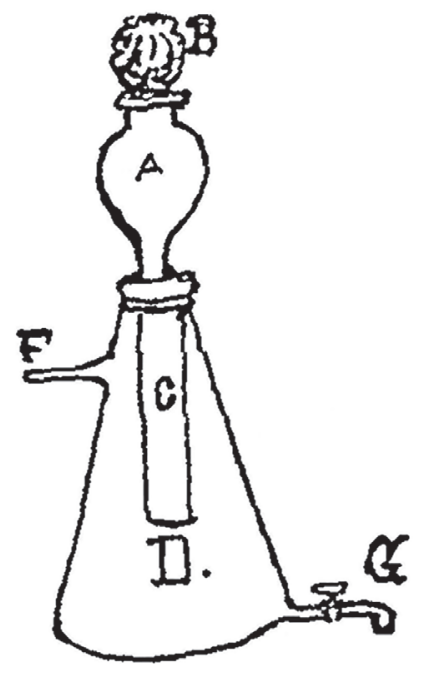

Figura 3. Aparato para esterilizar soluciones por filtración. Fuente: Manuel Urbina, “Trabajo inaugural”, La Farmacia, v. 13, n. 11,1904 , p. $225-233$

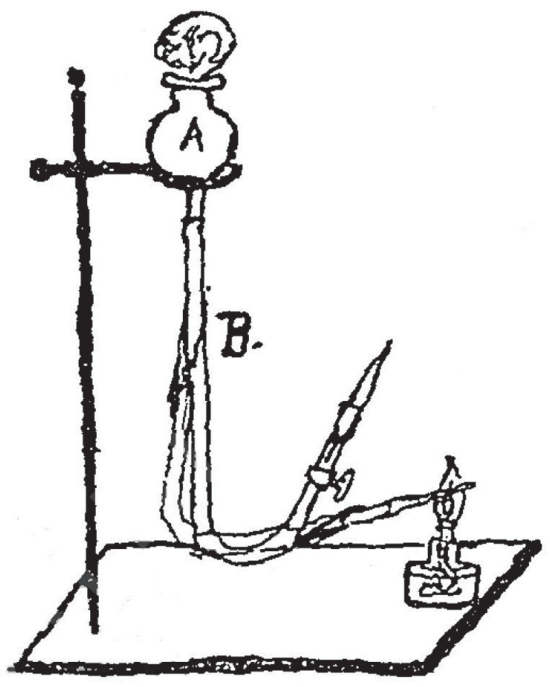

Figura 4. Aparato de Caturegli para llenar ampolletas. Fuente: Urbina, “Trabajo inaugural” 
cada una de las extremidades de la ampolleta. ${ }^{72}$ No hace falta mencionar que este procedimiento tenía que realizarse en condiciones asépticas.

Si se deseaba esterilizar y llenar ampolletas de forma rápida, cómoda y económica, se realizaba mediante vacío con el famoso aparato de Eury (figura 5), de uso frecuente en diversos países. Este aparato consistía en una probeta de pie (A), que llevaba en su interior una bujía Pasteur, la cual se conectaba por medio de un tubo de caucho y otro de cristal a una campana (B) que cubría un recipiente (C) con las ampolletas requeridas. Para trabajar con las ampolletas, éstas tenían que estar previamente cerradas por un lado. De la parte superior de la campana salía otro tubo (D) que comunicaba con una bomba neumática o una trompa de agua para vacío. El procedimiento era el siguiente: se ponía el líquido en la probeta y se iniciaba el vacío, con lo cual el líquido empezaba a caer en el recipiente interior. El aire de las ampolletas salía y cuando se dejaba entrar de nuevo el aire, éstas se llenaban por sí solas, cerrándolas después a la lámpara. ${ }^{73}$

Sin embargo, si no se requería preparar grandes cantidades de ampolletas, los boticarios mexicanos idearon otros métodos más sencillos para llenar estos envases, utilizando vacío generado por calor. Por ejemplo, el farmacéutico Manuel Urbina, desarrolló un procedimiento que consistía en:

[...] un vaso de bohemia (vaso de precipitado) el cual se llena del líquido, se ponen allí las ampolletas cerradas por un lado, se calienta por medio de una lámpara hasta llegar a la ebullición, se deja enfriar y las ampolletas se irán llenando a medida que se vaya enfriando el líquido; esto está fundado en que el aire es expulsado, en este caso, por medio de calor y en el otro (el método de Eury), por medio del vacío. ${ }^{74}$

Estos artículos publicados demuestran que la ampolleta inyectable fue bien recibida en México y que su fabricación y comercialización estuvo a cargo principalmente de los farmacéuticos y boticarios, dentro de sus establecimientos y negocios particulares. De igual manera, ponen en evidencia que en un principio, la ampolleta estéril fue más popular en México que en los Estados Unidos, sobre todo entre los dueños de farmacias.

${ }^{72}$ Luis F. Pérez, "De la esterilización de las soluciones de clorhidrato de cocaína", La Farmacia, v. 14, n. 11, 15 de noviembre de 1905, p. 243-251; Urbina, "Trabajo inaugural”.

${ }^{73}$ Idem.

${ }^{74}$ Idem. 


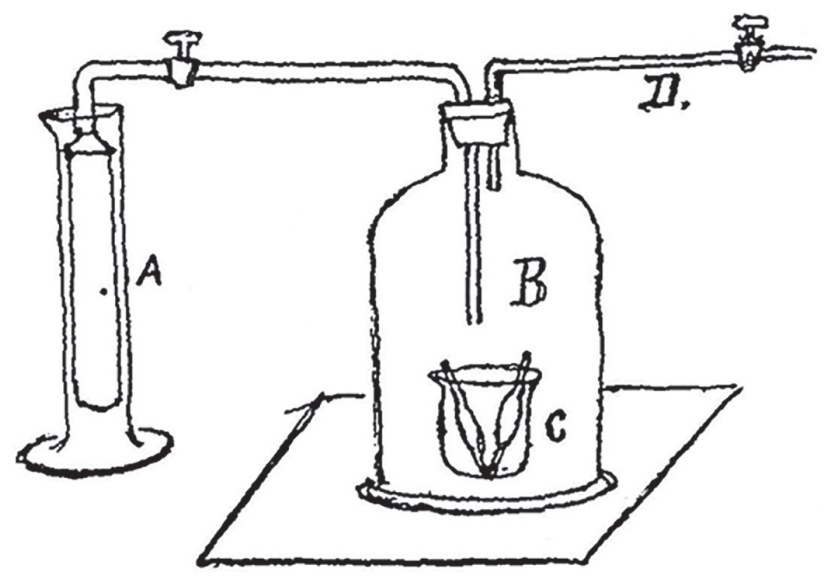

Figura 5. Aparato de Eury para esterilizar y llenar ampolletas.

Fuente: Urbina, "Trabajo inaugural”

Es importante señalar que durante esta época, entre algunos farmacéuticos y hombres de negocios, se aceptaba la idea de que la Botica del Hospital de Jesús, de la ciudad de México, era la primera en el continente americano en ocuparse de las ampolletas inyectables. Por ejemplo, el reconocido farmacéutico y empresario español Triunfo Bezanilla Testa, aseguraba entonces que:

Ya por los citados años y en el laboratorio a que se ha hecho referencia que era el de la farmacia del Hospital de Jesús, a cargo en aquel tiempo del profesor D. Juan B. Calderón, se confeccionaban las nuevas “formas” de medicamentos: perlas y cápsulas, gelatinas, comprimidos y tabletas, tinturas, extractos fluidos, sinapismos, ungüentos y pomadas, etc., toda la gama de la Farmacopea en preparaciones oficinales. Y fue entonces cuando surgió la importantísima forma del inyectable en ampollas de vidrio para empleo de una sola vez; habiéndole tocado al mencionado establecimiento ser el primero en el país y aún en América, que se ocupara de esa rama de la Farmacopoyética, al tiempo que su desarrollo estaba ya planteado en Francia, sin iniciarse siquiera en otros países de Europa, ni siquiera en los Estados Unidos de Norteamérica. ${ }^{75}$

75 Triunfo Bezanilla Testa, “La industria farmacéutica nacional”, Farmacoterapia, v. 1, n. 1,1947 , p. 6-7. 
A pesar de las declaraciones del farmacéutico Bezanilla, este artículo muestra que la producción de ampolletas inyectables podría haber iniciado antes en los Estados Unidos que en México. Como hemos visto, los primeros datos hallados sobre la fabricación local de ampolletas inyectables datan de 1896, en el caso de los Estados Unidos (con la introducción de los bulbos de cristal de Parke, Davis \& Company), y de 1904, en el de México (con los trabajos de la ya mencionada Botica del Hospital de Jesús). Sin embargo, como se mencionó al principio, el objetivo de este artículo no es determinar cuál fue el primer país americano que fabricó localmente ampolletas inyectables; si se desea esclarecer esto, es necesario realizar más investigaciones históricas sobre la llegada de las ampolletas a las diversas naciones del continente. Actualmente, la bibliografía sobre el tema es escasa por lo que se posee poca información al respecto.

La causa principal de la divergencia en la adopción de la ampolleta inyectable entre países como México y Estados Unidos fueron las influencias de los modelos farmacéuticos español y francés en el territorio mexicano. Estos modelos estaban basados profundamente en la medicina y la farmacia galénicas, que implicaban la elaboración de medicamentos en las farmacias o boticas. ${ }^{76} \mathrm{Si}$ bien el medicamento industrial, de origen europeo y estadounidense, ya empezaba a ganar terreno en el mercado mexicano y las farmacias locales incorporaban cada vez más en sus inventarios la medicina de patente y la especialidad farmacéutica (lo que causaba encono en los farmacéuticos institucionalizados al no poder verificar su composición, ya que estos productos llegaban en envases cerrados), un gran número de medicamentos en México seguía preparándose mediante fórmulas magistrales u oficinales. ${ }^{77}$

Otro factor importante que propició la fabricación de la ampolleta inyectable por los farmacéuticos y boticarios fue la ausencia de una industria farmacéutica mexicana a inicios del siglo xx y, en consecuencia, la falta de un modelo industrializador del medicamento como en Europa y Estados Unidos. Godínez y Aceves aseguran que en estos años los avances en la química mexicana no habían generado aún el interés por crear una industria de producción de drogas y medicamentos. De igual forma, también influyó

${ }^{76}$ Godínez y Aceves, "La regulación del medicamento industrial..."

${ }^{77}$ Mariana Ortiz Reynoso, "Farmacia química en el siglo XIX mexicano: una mirada a través de los alcaloides”, en Angélica Morales Sarabia y Mauricio Sánchez Menchero (coord.), Signa naturalia: concepciones y prácticas en torno a la materia médica, la farmacia y la salud ( ciones Interdisciplinarias en Ciencias y Humanidades, 2016, p. 163-197. 
la falta de empresarios mexicanos con capital suficiente para establecer este tipo de industria, además de la desconfianza de estos últimos en esta rama productiva. Asimismo, durante el Porfiriato, el gobierno federal no estaba particularmente interesado en la creación de una industria farmacéutica en territorio nacional, si bien otros sectores económicos (como el minero, petrolero y textil) acaparaban su atención. ${ }^{78}$

Pese a la ausencia de una industria farmacéutica local, las ampolletas inyectables comenzaron a incrementar su presencia en las farmacias mexicanas. En 1904, la empresa Rivera \& Compañía, de Guadalajara, Jalisco, buscaba comercializar soluciones estériles para inyecciones hipodérmicas. La etiqueta señalaba que estas soluciones estaban envasadas en "ámpulas cerradas a fuego". ${ }^{79}$ También se vendía en algunas droguerías el "Arrhenal Adrian”, consistente en ampolletas de metil-arseniato di-sódico, arsénico orgánico para inyecciones hipodérmicas. ${ }^{80}$ Hacia 1906, la Droguería del Factor, de la familia Grisi, comercializaba el "Roburol Brissac", que consistía en formiato de sosa en ampolletas para el tratamiento de la neurastenia, fatiga cerebral, anemia y cansancio por agotamiento físico. ${ }^{81}$ Hacia 1908, en las boticas mexicanas se vendían ampolletas tanto de confección nacional como importadas desde Italia o Francia por empresas extranjeras establecidas en el mercado local, como la italiana Carlo Erba, que vendía soluciones estériles de cocaína para anestesia. ${ }^{82}$

Durante el festejo del centenario del inicio del movimiento de Independencia nacional, en septiembre de 1910, se realizó una exposición en la ENM de la ciudad de México, para mostrar los avances escolares de esta institución. En la sección de química de dicha exposición, se exhibieron diversos tipos de ampolletas, sueros y los diferentes diseños de aparatos utilizados para su fabricación. ${ }^{83}$ De igual forma, el profesor Antonio Iriarte y Rico, miembro de la SFM, aseguraba que un gran número de farmacéuticos nacionales ya dominaban el proceso de esterilización para el desarrollo de formas farmacéuticas inyectables por vía hipodérmica, utilizando princi-

${ }^{78}$ Godínez y Aceves, Proyectos, realidades y utopías...

${ }^{79}$ Instituto Mexicano de la Propiedad Industrial (en adelante, IMPI), marca 4770, fecha legal: 3 de agosto de 1904 .

80 "Arrhenal", El Imparcial, 20 de julio de 1902.

81 "El Roburol Brissac al Formiato de Sosa", El Imparcial, 24 de junio de 1906.

${ }^{82}$ Joseph Fabra, "Mexican Pharmacies", American Druggist and Pharmaceutical Record, 28 de diciembre de 1908; IMPI, exp. 11761, fecha legal: 31 de diciembre de 1910.

${ }^{83}$ Martha Eugenia Rodríguez, "La Escuela Nacional de Medicina en los tiempos del centenario”, Revista Médica del Instituto Mexicano del Seguro Social, v. 48, n. 4, 2010, p. 405-414. 
palmente ampolletas de cristal. Además, estos medicamentos parenterales eran iguales en calidad y más económicos que los de origen extranjero, gozando de gran aceptación entre los médicos del país. ${ }^{84}$

Si bien en 1910 aún no existían compañías productoras de medicamentos donde se pudiera aplicar la bacteriología de forma industrial, los estudiantes conocían detalladamente los fundamentos teórico-prácticos de esta ciencia. Desde 1908 estaba presente la cátedra de Bacteriología en el plan de estudios de la carrera de farmacia de la $\mathbf{E N M},{ }^{85}$ pero ya antes la enseñanza de esta disciplina y su aplicación en la fabricación de inyectables tenían lugar en las boticas de reconocidos farmacéuticos, a las cuales diversos alumnos acudían a realizar sus prácticas. Asimismo, es importante señalar que, como el mencionado caso de la Botica del Hospital de Jesús, muchos de los propietarios de farmacias célebres eran profesores de la ENM, así como investigadores del prestigioso Instituto Médico Nacional (IMN). De esta forma, los conocimientos adquiridos en las farmacias sobre la preparación de ampolletas inyectables pudieron ser incluidos y estandarizados en la obra literaria más importante del IMN, publicada hacia 1913 con el nombre de Farmacología nacional.

Las ampolletas inyectables en la farmacología nacional

El IMN es hoy considerado por los historiadores de la ciencia como el centro científico más importante de su tiempo, en el México de finales del siglo xix y principios del xx. Fue fundado en 1888 por iniciativa del gobierno a través de la Secretaría de Fomento, con la función principal de desarrollar una terapéutica nacional por medio del estudio de la flora y fauna medicinales, las aguas minerales y la climatología y geografía médicas. Hacia 1890, la institución estaba dividida en cinco secciones: 1) Historia Natural; 2) Química Analítica; 3) Fisiología Experimental; 4) Terapéutica Clínica; y 5) Climatología y Geografía Médica. Las primeras cuatro secciones trabajaban de manera estrecha; estaban organizadas de tal forma

\footnotetext{
${ }^{84}$ Antonio Iriarte y Rico, Evolución de la farmacia en México durante el primer siglo de nuestra independencia, México, Tipografía Vda. de F. Díaz de León, Sucs., 1911, p. 14.

85 Sandra Martínez Solís, Patricia Aceves Pastrana y Alba Morales Cosme, "La transformación de una profesión: las primeras farmacéuticas mexicanas”, en México en el siglo XX, México, Archivo General de la Nación, 1999, p. 613-638.
} 
para que los proyectos siguieran un orden determinado y de esta manera pudiera maximizarse la obtención de resultados. ${ }^{86}$

La Primera Sección de Historia Natural describía e identificaba las especies vegetales y animales con posibilidades de utilizarse en la elaboración de medicamentos. Una vez identificada la especie que contenía una droga determinada, las muestras pasaban a la Segunda Sección de Química Analítica, que realizaba el análisis químico para conocer su composición e identificar las sustancias responsables del efecto terapéutico. Posteriormente, en la Tercera Sección de Fisiología Experimental, se comprobaba la efectividad o la posible toxicidad de las sustancias aisladas a través de experimentos fisiológicos en animales. Finalmente, los resultados transitaban a la Cuarta Sección de Terapéutica Clínica, donde se probaría la eficacia terapéutica de los fármacos en pacientes enfermos, a partir de las diversas formas farmacéuticas propuestas para su dosificación y administración. ${ }^{87}$

En 1904, dentro de la Cuarta Sección se creó el Departamento de Química Industrial, destinado a la obtención de alcaloides y a la producción de fórmulas farmacéuticas con los principios activos estudiados en las primeras cuatro secciones. ${ }^{88}$ La Quinta Sección, de Climatología y Geografía Médica, era la más independiente de todas; sin embargo, también estaba insertada en el objetivo de la institución: mejorar las condiciones higiénicas del país, fomentar el crecimiento de la inversión extranjera y nacional e impulsar el uso de los recursos naturales locales. ${ }^{89}$

Durante su existencia, trabajaron en el IMN algunos de los científicos nacionales y extranjeros más importantes de la época. Dentro de sus instalaciones colaboraron médicos, botánicos, naturalistas, veterinarios, entre otros expertos, pero sobre todo ahí confluyeron diversos farmacéuticos mexicanos que, además de realizar investigaciones sobre el efecto terapéutico de plantas nacionales utilizadas en la medicina tradicional, también desempeñaron funciones administrativas relevantes para la institución.

Por ejemplo, en 1904, Ricardo Caturegli se incorporó como preparador y ayudante químico farmacéutico en el Departamento de Química Industrial,

${ }^{86}$ Nina Hinke, El Instituto Médico Nacional. La política de las plantas y los laboratorios a finales del siglo XIX, México, Universidad Nacional Autónoma de México, Coordinación de Humanidades/Instituto Politécnico Nacional, Centro de Investigación y de Estudios Avanzados, 2012, p. 50.

${ }^{87}$ Idem.

88 Ortiz, "Farmacia química en el siglo xıx mexicano..."

${ }^{89}$ Hinke, El Instituto Médico Nacional..., p. 68, 69. 
donde permaneció por varios años como encargado, junto con los profesores James McConnell Sanders y Manuel Urbina. ${ }^{90}$ Caturegli también se ocupó del establecimiento de la botica de la Primera Sección. Posteriormente, fue profesor responsable de las academias de Química de la Escuela Nacional Preparatoria ${ }^{91}$ y de la cátedra de Análisis Químico en la ENM. Se considera que Ricardo Caturegli fue uno de los principales impulsores de la química y la farmacia mexicanas, ya que en las décadas siguientes tendría un rol significativo tanto en la creación de sociedades y asociaciones gremiales como en el proceso de profesionalización de estas disciplinas en el país. ${ }^{92}$

Por otra parte, el mencionado farmacéutico Juan B. Calderón también se incorporó al Departamento de Química Industrial del IMN hacia 1908, en el cargo de ayudante químico farmacéutico, sustituyendo a Ricardo Caturegli cuando este último pidió un permiso temporal. Al parecer, el tiempo que Calderón trabajó en este centro fue breve, encargándose de investigaciones sobre plantas como el malacate (Exostemma mexicanum) y de la extracción de sustancias terapéuticas de la planta conocida como estafiate. ${ }^{93}$ Como se ha mencionado, Calderón era profesor de la carrera de Farmacia de la ENM, miembro activo de la SFM e integrante de la Comisión Permanente de la Farmacopea (encargada de redactar y actualizar este documento); además, se le considera uno de los principales responsables de la publicación de las farmacopeas de 1896 y 1904.

A partir de 1910, los investigadores del IMN se dieron a la tarea de redactar una obra magna, que reuniría todas las investigaciones y contribuciones obtenidas en 25 años de trabajo. Este documento titulado Farmacología nacional se publicó hasta 1913, e incluía las características específicas de distintas plantas mexicanas, junto con las prácticas más comunes desarrolladas en las farmacias nacionales. Es decir, integraba la nueva terapéutica que los científicos del ImN buscaban introducir en México para su utilización por los pro-

${ }^{90}$ Leopoldo Flores, "Junta mensual del 31 de octubre de 1905”, Anales del Instituto Médico Nacional, n. 7, 1905, p. 429-439.

${ }^{91}$ Leopoldo Flores, “Junta mensual del 30 de abril de 1908”, Anales del Instituto Médico Nacional, n. 10, 1908, p. 143-146.

92 Liliana Schifter y Patricia Aceves, "Los farmacéuticos y la química en México (19031919): prácticas, actores y sitios”, Estudios de Historia Moderna y Contemporánea de México, n. 51, enero-junio 2016, p. 72-92.

${ }_{93}$ James McConnell Sanders, "Departamento de Química Industrial”, Anales del Instituto Médico Nacional, v. 10, 1908, p. 127. 
fesionales de la salud. ${ }^{94}$ Diversas investigaciones históricas han subrayado la trascendencia de la aparición de Farmacología nacional, ya que muestra el interés por aprovechar los recursos naturales y actualizar el conocimiento clínico de la época, en medio del difícil escenario político y social que atravesaba entonces el país, con el inminente movimiento de Revolución.

La publicación de la Farmacología nacional estandarizó por primera vez los procesos de esterilización y de preparación de ampolletas inyectables. De acuerdo con este texto, las ampolletas con medicamentos inyectables son "recipientes de vidrio, de formas y capacidades diversas, que contienen la cantidad de medicamento inyectable que empleará el médico en una sola inyección". ${ }^{95}$ El capítulo de esterilización señala que debían seleccionarse ampolletas fabricadas con vidrios sin características plúmbicas (o sea relativas al plomo), ni calcáreas (a la cal) y que no comunicaran alcalinidad al agua, ni siquiera en una mínima cantidad. Para esto, se recomendaba usar los vidrios de tipo sérax. Asimismo, se describen los procedimientos cualitativos para asegurar las propiedades adecuadas de los cristales a utilizar. ${ }^{96}$

Según este documento, los métodos para esterilizar y llenar ampolletas dependían de las características físicas de estos envases y de las propiedades fisicoquímicas del principio activo en solución. Por ejemplo, si las ampolletas estaban abiertas en sus dos extremos, se llenaban aspirando directamente por un tubo de caucho y después se cerraban los extremos por medio de calor. Si estaban abiertas sólo por un extremo, el procedimiento variaba dependiendo de la termolabilidad del fármaco y de la existencia de partículas en suspensión. En caso de que el fármaco fuera estable a $120^{\circ} \mathrm{C}$ (la temperatura de esterilización) y no se observaran partículas en suspensión, se colocaba la solución en un cristalizador, sumergiendo las ampolletas en el líquido con el extremo abierto hacia abajo. Después se sostenían con un diafragma perforado, hecho de vidrio o metal plateado, para que el extremo abierto no tocara el fondo. Entonces se cubría el cristalizador con otro de mayor diámetro y, montados de esta forma, se introducían en un autoclave. Se calentaban a $120^{\circ} \mathrm{C}$ (durante un tiempo de 30 minutos), se realizaban varias descompresiones, se dejaba enfriar el autoclave y poste-

${ }^{94}$ Patricia Aceves, Liliana Schifter y Angélica Morales, "La farmacología nacional y la farmacopea mexicana”, en João Rui Pita y Ana Leonor Pereira (coord.), Histórias da saúde. Estudos do século Xx, Coimbra, Imprensa da Universidade de Coimbra, 2012, p. 199-216.

${ }^{95}$ Instituto Médico Nacional, Farmacología nacional, México, Tipografía Económica, 1913, p. 502.

${ }^{96}$ Ibidem, p. 502, 503. 
riormente se hacía penetrar aire filtrado de manera paulatina. Una vez llenas las ampolletas, se cerraban por calor. ${ }^{97}$

Si el fármaco se degradaba a $120^{\circ} \mathrm{C}$ y no existían partículas suspendidas, se volvían a colocar las ampolletas en un cristalizador que contenía la solución, se cubría con otro cristalizador como en el caso anterior y se colocaban en una campana para vacío. Después de aplicado el vacío, se dejaba entrar lentamente aire filtrado. Al llenarse las ampolletas, se cerraban de nuevo por calor. Se debía considerar que, en los dos procedimientos anteriores, las ampolletas tenían que llenarse hasta las $4 / 5$ partes de su capacidad. Finalmente, si se notaba la presencia de partículas suspendidas, se debía llenar cada ampolleta con una pequeña jeringa, agitando con frecuencia la suspensión del fármaco para evitar la sedimentación. ${ }^{98}$

Podemos notar que los procedimientos con ampolletas que se utilizaban en México durante esta época eran similares a los empleados en Estados Unidos, como la esterilización por autoclave y el llenado por medio de vacío o con la ayuda de una jeringa hipodérmica. El hecho de que estas técnicas se incluyeran en la Farmacología nacional significa que los investigadores del IMN las conocían, aprobaban y aplicaban; sin embargo, quizás no fueron desarrolladas y perfeccionadas dentro de las instalaciones del IMN, sino en las boticas y farmacias de los mismos científicos. Esta podría ser la razón de que no estén documentados medicamentos en forma de ampolletas inyectables en las revistas oficiales de la institución, El Estudio y los Anales del Instituto Médico Nacional, donde se publicaban todos los informes y resultados obtenidos en sus investigaciones.

Tampoco están en los informes periódicos del IMN, posiblemente porque la orientación de los proyectos de investigación del Departamento de Química Industrial, que poseía maquinaria especializada para fines farmacéuticos, era la formulación de medicamentos comunes con fármacos derivados de la terapéutica nacional, cuyo origen, composición química y efectividad habían sido comprobados en el mismo imN. Así, el énfasis del IMN fue en la producción de medicamentos líquidos orales ya conocidos, principalmente extractos con principios activos de especies vegetales, y no en las formas farmacéuticas parenterales. La innovación del IMN radicó en el estudio y aislamiento del principio activo novedoso y estandarizado (es decir, en el origen nacional del fármaco, la originalidad de la molécula y la

97 Ibidem, p. 503.

${ }^{98}$ Idem. 
verificación de su identidad, la pureza de la fórmula y la eficacia clínica del producto), más no en el desarrollo de formas farmacéuticas emergentes.

Sin embargo, como se ha dicho, las ampolletas inyectables eran sistemas farmacéuticos familiares a los investigadores del IMN y probablemente la inclusión de técnicas de esterilización y de elaboración de medicamentos parenterales en la Farmacología nacional se debió a la práctica que dichos expertos tenían al mismo tiempo en sus boticas, donde se aplicaban estos procesos y se enseñaban a los alumnos. El multicitado profesor Juan B. Calderón, de la Botica del Hospital de Jesús, vendía sueros asépticos e inyecciones hipodérmicas desde 1904, aunque existieron otros personajes. En su artículo sobre los orígenes de la industria farmacéutica mexicana, Godínez y Aceves aseguran que Calderón fue uno de los precursores de la industrialización de la farmacia en México, ya que su botica sentó las bases para el establecimiento en las décadas siguientes de diversas compañías dedicadas a la producción de inyectables a gran escala. ${ }^{99}$

Asimismo, muchos estudiantes que llevaron a cabo sus prácticas profesionales elaborando inyectables en las farmacias, se incorporaron posteriormente al IMN, como los casos de Ricardo Caturegli y Manuel Urbina ya mencionados. También es importante considerar la implicación en esto de la SFM, a la que estaban asociados varios científicos del IMN. Ante la falta de una farmacopea actualizada (pues la última había sido publicada en 1904), posiblemente los farmacéuticos de la SFM consideraron que la Farmacología nacional de 1913 podía llenar el vacío existente en los campos de la terapéutica y de las ampolletas inyectables. Tampoco hay que olvidar las valiosas aportaciones a este documento de los demás profesionales del IMN, como los médicos, los botánicos y los naturalistas. Finalmente, con la clausura del IMN en 1915 (por órdenes de los gobiernos revolucionarios, quienes consideraban que esta institución no era necesaria para la vida nacional), los derechos literarios de la Farmacología nacional fueron cedidos a la SFM, la cual tomó esta obra como referencia principal para la redacción de la siguiente Farmacopea mexicana, que se publicaría hasta 1925.

${ }^{99}$ Godínez y Aceves, "El surgimiento de la industria farmacéutica...” 
Los inicios de la industria de inyectables en México

Como hemos visto, desde su llegada a territorio mexicano, los medicamentos inyectables y las ampolletas estuvieron a cargo especialmente de los boticarios, quienes llevaban a cabo producciones a pequeña y mediana escala en sus negocios particulares. Si bien es cierto que durante el Porfiriato, el país alcanzó cierto grado de industrialización y existían diversas compañías de capital mexicano y extranjero realizando operaciones comerciales en el mercado interno, a inicios del siglo xx, diversos factores nacionales e internacionales no habían permitido aún el establecimiento de una industria farmacéutica. El inicio de la Revolución Mexicana en 1910 tampoco permitió el surgimiento de nuevos sectores económicos. Se considera que la guerra civil no causó grandes pérdidas a los empresarios establecidos en México, dado que no desmantelaron sus compañías ni retiraron sus capitales; sin embargo, la industria nacional permaneció inactiva durante casi todo el conflicto. ${ }^{100}$

Ante la falta de compañías interesadas en fabricar ampolletas inyectables en la República Mexicana, la demanda popular de estos medicamentos no era cubierta totalmente por los boticarios, por lo que se completaba con productos de importación. No obstante, la escasez de materias primas extranjeras en el mercado mexicano, causada por la ocupación estadounidense del puerto de Veracruz y el comienzo de la Primera Guerra Mundial en 1914, provocó que México incrementara su producción local de soluciones inyectables. En este año, ante la incertidumbre de la guerra, en la Escuela Nacional Preparatoria se instalaron laboratorios para la fabricación de ampolletas. El aceite necesario para su elaboración fue aportado por fábricas privadas, el autoclave que se utilizó para esterilizar los materiales fue donado por el Instituto Bacteriológico Nacional, mientras que los utensilios e instrumentos requeridos fueron obsequiados por algunos farmacéuticos capitalinos como los señores Bustillos, Río de la Loza y Bezanilla, entre otros empresarios. ${ }^{101}$

El surgimiento de la industria farmacéutica en México tendría lugar hasta el periodo posrevolucionario (1917-1940), con la llegada e instalación

${ }^{100}$ Mario Ramírez Rancaño, "El Primer Congreso de Industriales y la Constitución Política”, en Julio Labastida et al. (comp.), Grupos económicos y organizaciones empresariales en México, México, Alianza Editorial Mexicana/Universidad Nacional Autónoma de México, Instituto de Investigaciones Sociales, 1986, p. 83-122.

101 “Una gran obra humanitaria en la Esc. Preparatoria”, El Imparcial, 30 de mayo de 1914. 
de diversas filiales de compañías extranjeras que buscaban incursionar en una rama de la economía que había sido poco explotada. Principalmente arribaron empresas alemanas, estadounidenses, francesas y húngaras, que en un principio deseaban vender artículos importados en el mercado y que después iniciarían la fabricación de productos medicinales a gran escala. Al mismo tiempo, diversos inversionistas mexicanos, al percatarse del éxito de las firmas extranjeras, también fundaron sus propias compañías productoras de medicamentos, algunas de las cuales evolucionaron a partir de pequeñas boticas o farmacias. ${ }^{102}$ Es importante subrayar que la industrialización farmacéutica en el territorio mexicano tuvo lugar de forma tardía en comparación con los Estados Unidos (en donde había comenzado desde la segunda mitad del siglo XIX).

Una de las primeras empresas establecidas en México que decidió incursionar en el mercado de inyectables fue Triunfo Bezanilla \& Companía. Esta firma existía en el país desde 1905; era propiedad del farmacéutico español Triunfo Bezanilla Gómez y de su hijo Triunfo Bezanilla Testa. ${ }^{103}$ Si bien desde su fundación comercializaba preparaciones estériles, hasta 1911 inició la fabricación masiva de estos productos. ${ }^{104}$ En 1917, Triunfo Bezanilla \& Companía. se denominaba a sí misma el primer laboratorio nacional de inyectables que cumplía con todas las exigencias sanitarias y clamaba ser la empresa pionera en México en esta rama de la industria farmacéutica. En los anuncios comerciales, se aseguraba que las preparaciones inyectables Bezanilla "han competido siempre con las mejores del extranjero en calidad y precio por su esmerada confección, exacta dosificación y absoluta asepsia”. ${ }^{105}$ Asimismo, la empresa patentó modelos de ampolletas para la esterilización, conservación y aplicación de sueros terapéuticos artificiales. ${ }^{106}$

Otra compañía que también comenzó la fabricación de inyectables fue el Laboratorio El Águila, propiedad de la sociedad mexicana Garza Treviño y Companía. En 1919, se describía a esta empresa como poseedora de una

${ }^{102}$ Godínez y Aceves, Proyectos, realidades y utopías...

${ }^{103}$ Alba Dolores Morales Cosme y Carlos Viesca Treviño, “El Laboratorio Químico Farmacéutico de T. Bezanilla e Hijos, 1905-1919”, Boletín de la Sociedad Química de México, v. 9, n. 3, 2015, p. 16-21.

${ }^{104}$ AHSSA, Fondo Salubridad Pública, Sección Inspección de Farmacias, caja 2, exp. 24.

${ }^{105}$ Triunfo Bezanilla y Cía., "Droguería, farmacia de primera clase y laboratorios”, La Farmacia, 1 de octubre de 1917.

${ }^{106}$ IMPI, patente 8884, fecha legal: 26 de febrero de 1909. 
maquinaria notable por su sencillez, limpieza y práctico funcionamiento en sus departamentos de producción. Se aseguraba que su sección de inyectables estaba dotada de un sistema perfecto de aparatos para filtrar soluciones, llenar y cerrar ampolletas de todos los tamaños, además de poseer un magnífico autoclave de gran capacidad y de invención netamente mexicana, con una tecnología que garantizaba una perfecta esterilización. ${ }^{107}$ Esto convertía al Laboratorio El Águila en una de las pocas empresas mexicanas que utilizaba maquinaria de origen nacional en su infraestructura, ya que a inicios del siglo xx, la industria local recurría a la adquisición de tecnología extranjera para la fabricación de productos.

Durante las décadas de los veinte y treinta, la comercialización de medicamentos inyectables en presentación de ampolletas creció exponencialmente en el mercado mexicano. Diversas empresas de capital mexicano y extranjero introdujeron una gran cantidad de productos parenterales, desde vacunas, sueros, analgésicos, antirreumáticos, tónicos y reconstituyentes, entre otros. Aunque antes de la Segunda Guerra Mundial no existían los antibióticos, se utilizaban diversos medicamentos antiinfecciosos y antimicrobianos. No es el objetivo de este trabajo describir todos los inyectables en ampolletas que existían en estos años, pero enseguida se hará mención de algunos de ellos.

La compañía alemana Schering, aún sin instalaciones en México, vendía a través de sus representantes el Arthigón (una de las primeras vacunas contra la gonorrea), el Atophanil (antigotoso o antirreumático) y la Urotropina (desinfectante y antibacteriano). ${ }^{108}$ La Química Industrial Bayer, Meister, Lucius, Weskott \& Companía, también de capital alemán, comercializaba en el país un suero antigripal contra estreptococos y neumococos. ${ }^{109}$ Beick Félix \& Companía, propiedad de empresarios teutones, distribuía la Serula Behring, una combinación de jeringa y ampolleta que contenía agua esterilizada para su uso inmediato. ${ }^{110}$ Para conciliar el sueño, la alemana Merck-México introdujo el Escofedal con bromhidrato de escopolamina; ${ }^{111}$ y el Grupo Roussel, S. A., de capital franco-alemán, el Benzo Ginestryl 5 con benzoato de di-hidro-foliculina para la insuficiencia

107 “Una visita al Laboratorio El Águila”, La Farmacia, v. 2, n. 5, 1919, p. 86.

108 “A los señores médicos”, El Informador, 7 de marzo de 1925.

${ }^{109}$ Química Industrial Bayer, Meister, Lucius, Weskott \& Cía., "Suero Antigripal Bayer-Meister Lucius”, Gaceta Médica de México, noviembre de 1929.

${ }^{110}$ Beick Félix \& Cía., "Serula Behring”, Gaceta Médica de México, julio de 1929.

${ }^{111}$ Merck-México, “Escofedal”, Gaceta Médica de México, 31 de agosto de 1940. 
ovárica acentuada. ${ }^{112}$ La empresa húngara Productos Farmacéuticos, S. A., distribuía el Dyscural Chinoín con una combinación de ampolleta y tableta para la amibiasis. ${ }^{113}$

Entre las empresas mexicanas, los Laboratorios Terapia manufacturaban el Artrodyol para el tratamiento del reumatismo y la evacuación de la bilis (por poseer un efecto colagogo). ${ }^{114}$ La empresa Farmamex, S. A., fabricaba el Sulfarsenol en ampolletas para el tratamiento de la sífilis, el paludismo y la erisipela. ${ }^{115}$ Los Laboratorios Químico-Biológicos México Industrial comercializaban el Plasminol para adultos, un suero neurotónico compuesto de cacodilato de sodio, para tratar la convalecencia de enfermedades infecciosas. ${ }^{116}$ Las ampolletas Ionine, de los Laboratorios Ionine, combatían la tuberculosis pulmonar y otros padecimientos de las vías respiratorias. ${ }^{117}$ Finalmente, los Laboratorios Hormona, especializados en productos opoterápicos, vendían el Bazo-hígado Potenciado Hormona para tratar las anemias palúdicas ${ }^{118}$ y el Proglobin Hormona destinado a las anemias secundarias. ${ }^{119}$

Asimismo, en estas décadas, diversos inventores y empresas patentaron en México prototipos de ampolletas para diversos usos. En 1921, los mexicanos Bernardo Núñez y Leonardo Zimbrón, de la Farmacia Velasco de la ciudad de México, patentaron un "frasco-ampolleta" ${ }^{120}$ y la compañía francesa Boulanger Dausseet, un ámpula para inyecciones. ${ }^{121}$ El empresario suizo Manuel Grey patentó en 1923 la “Ampolleta Grey”, un modelo

112 Grupo Roussel, S. A., "Preparaciones foliculínicas Roussel”, Gaceta Médica de México, 30 de junio de 1938.

${ }^{113}$ Productos Farmacéuticos, S. A., “Dyscural Chinoín”, Gaceta Médica de México, agosto de 1933.

${ }^{114}$ Unión Médica Mexicana, S. C. L., “Artrodyol”, Gaceta Médica de México, julio de 1932.

115 Farmamex, S. A., “Ampolletas Sulfarsenol”, Gaceta Médica de México, julio de 1932.

${ }^{116}$ Laboratorios Químico-Biológicos México Industrial, "Plasminol”, Gaceta Médica de México, junio de 1933.

117 “Laboratorios Ionine, S. A.”, El Informador, 2 de abril de 1933.

${ }^{118}$ Laboratorios Hormona, "Bazo-hígado Potenciado Hormona", Gaceta Médica de México, 30 de abril de 1937.

${ }^{119}$ Laboratorios Hormona, "Proglobin Hormona", Gaceta Médica de México, 31 de diciembre de 1937.

${ }^{120}$ IMPI, patente 4752, fecha legal: 31 de agosto de 1921; fecha de concesión: 9 de septiembre de 1921.

${ }^{121}$ IMPI, patente 20541, fecha legal: 3 de junio de 1921; fecha de concesión: 3 de agosto de 1921. 
de ampolleta-frasco para soluciones o líquidos inyectables. ${ }^{122} \mathrm{La}$ inventora mexicana Beatriz Eguiluz Paredes, de la empresa El Proveedor Obstétrico, patentó en 1926 una ampolleta gotero. ${ }^{123}$ Por último, en 1934 los laboratorios Pharmakón, S. A., y el mexicano Mariano Narváez patentaron una "ampolleta gemela" con dos compartimentos en el interior, uno para las sustancias en polvo y el otro para los líquidos. Esta invención evitaba que se utilizaran dos ampolletas para cada tipo de sustancia, permitiendo que al momento de la inyección se pudieran mezclar rápidamente dentro de una sola ampolleta. ${ }^{124}$

Hacia 1940, los productos estériles significaban una parte importante en las ventas de la joven industria farmacéutica mexicana, gracias a que las empresas ya contaban con la tecnología necesaria para su fabricación y acondicionamiento. De acuerdo con el Censo Industrial de 1940 (que recopilaba datos de 1939), las empresas farmacéuticas instaladas en México poseían en total 48 autoclaves, 1 máquina cerradora de ampolletas, 6 máquinas cortadoras de ampolletas, 1 máquina enfriadora de sueros, 6 esterilizadores, 1 filtro para sueros, 4 máquinas grabadoras de ampolletas, 11 impresoras de ampolletas, 17 máquinas para llenar ampolletas, 5 sopletes para cerrar ampolletas y 3 máquinas selladoras de ampolletas. La producción anual de ampolletas (como envases) era de $\$ 992418.00$ pesos mexicanos; lo que representaba el $4.2 \%$ de la producción total anual de la industria farmacéutica, que fue de $\$ 23504360.00 .^{125}$

Al igual que en los Estados Unidos, la llegada de los antibióticos durante la Segunda Guerra Mundial hizo despegar la industria de los medicamentos inyectables en México. El modelo de desarrollo económico que se practicó en el país después de la guerra, conocido como de sustitución de importaciones, permitió que la fabricación de ampolletas inyectables contara con incentivos arancelarios en el territorio mexicano, los cuales buscaban de-

${ }^{122}$ IMPI, patente 4943, fecha legal: 11 de junio de 1923; fecha de concesión: 15 de junio de 1923.

${ }^{123}$ IMPI, patente 25766, fecha legal: 8 de marzo de 1926; fecha de concesión: 17 de marzo de 1926.

${ }^{124}$ IMPI, patente 35316, fecha legal: 24 de septiembre de 1934; fecha de concesión: 25 de octubre de 1934 .

${ }^{125}$ Secretaría de la Economía Nacional, Dirección General de Estadística, "Productos farmacéuticos”, en Tercer Censo Industrial de los Estados Unidos Mexicanos, México, Secretaría de la Economía Nacional, Dirección General de Estadística, 1944, p. 7-41. 
sarrollar el mercado interno e impulsar la producción nacional. ${ }^{126}$ Algunas empresas que destacaron en este rubro fueron Ampolletas Monterrey, S. A., de Monterrey, Nuevo León, e Igmer, del Distrito Federal. De igual forma, durante las décadas de los años cuarenta y cincuenta, muchas compañías farmacéuticas nacionales y extranjeras crearon departamentos especializados en antibióticos dentro de sus instalaciones.

Sin embargo, Godínez, Aceves, Corona y Cárdenas aseguran también que, después de la guerra, las compañías instaladas en México se convirtieron principalmente en envasadoras de sustancias antibióticas extranjeras, ya que muy pocas realizaban procesos de semisíntesis molecular. La mayor parte de las materias primas que se utilizaban en la producción nacional eran de importación. Esta falta de innovación no permitió a la industria farmacéutica mexicana competir con su similar estadounidense, la cual ya se había posicionado como la líder mundial en este mercado. A pesar de esto, el incremento de presentaciones antibióticas en las farmacias trajo consigo grandes beneficios a la población mexicana, como el mejoramiento de los servicios sanitarios y el incremento en la esperanza de vida. ${ }^{127}$

\section{Conclusiones}

Durante los últimos años del siglo xix y los primeros del xx, los procesos de introducción de las ampolletas inyectables en México y Estados Unidos presentaron diversas divergencias, determinadas por las características de la práctica farmacéutica en cada país. En Estados Unidos, donde predominaba el modelo anglosajón de industrialización del medicamento, la ampolleta inyectable no fue bien recibida por los boticarios, quienes la consideraban compleja de elaborar en sus establecimientos, además de poco rentable. No obstante, los rasgos particulares de la farmacia estadounidense, heredados de las naciones de la Europa Central, permitieron la adopción rápida de las ampolletas por parte de las grandes empresas farmacéuticas, quienes las utilizaron para el envase y la producción a gran escala de soluciones estériles.

126 "Autorización que exime de impuestos a Ampolletas Monterrey, S. A. Secretaría de Hacienda y Crédito Público”, Diario Oficial de la Federación, 25 de marzo de 1943.

${ }^{127}$ Godínez, Aceves, Corona y Cárdenas, “Introducción de los antibióticos...”, p. 103-133. 
Por otra parte, la práctica farmacéutica que predominaba en México durante esta época, con características heredadas de la farmacia mediterránea, permitió que la ampolleta inyectable gozara de popularidad desde su llegada y que fuera arropada rápidamente por los boticarios y farmacéuticos mexicanos. Sin embargo, la producción de ampolletas en México comenzó a pequeña o mediana escala, ante la ausencia de una industria farmacéutica nacional antes de la Primera Guerra Mundial. Fue hasta la década de los años veinte y treinta cuando comenzó la producción masiva de ampolletas inyectables, no obstante, de forma tardía comparada con Estados Unidos.

Respecto de los aparatos y técnicas de esterilización o preparación de ampolletas inyectables, pudimos encontrar distintas similitudes entre los farmacéuticos mexicanos y estadounidenses. Los profesionales de cada país conocían los procedimientos más novedosos en este campo, en los cuales predominaba el uso del autoclave y el llenado de ampolletas por vacío. De igual forma, México y Estados Unidos estandarizaron estos procedimientos en sus códigos oficiales con pocos años de diferencia, en los casos de la USP de 1910 y la Farmacología nacional de 1913. Además, en cada nación existieron investigadores locales que patentaron distintas invenciones e innovaciones, destacando las combinaciones ampolleta-jeringa o las ampolletas con varios compartimentos.

El surgimiento de los antibióticos durante la Segunda Guerra Mundial dio un impulso importante a la fabricación de medicamentos inyectables en los dos países. No obstante, la investigación científica intensiva que tenía lugar en la industria farmacéutica de Estados Unidos (otra característica del modelo anglosajón) permitió que ésta liderara el mercado mundial de antibióticos, incluso sobre las industrias de países europeos. Por su parte, las compañías farmacéuticas de capital mexicano, que fomentaban más la producción que la investigación, no lograron competir con las empresas estadounidenses en esta rama. Sin embargo, para estos años, la fabricación de ampolletas inyectables ya significaba un rubro importante de la industria farmacéutica mexicana, lo cual disminuyó la dependencia de importaciones y trajo beneficios considerables para la población.

En conclusión, el análisis de los procesos de adopción de la ampolleta inyectable en México y Estados Unidos en el cambio del siglo xix al xx muestra que el ejercicio de una profesión es influido por las características sociales, científicas, institucionales, políticas y económicas de cada nación. De igual forma, el estudio de estas particularidades permite entender la situación actual de la profesión y la industria farmacéutica de estos países. Esperamos que los 
aportes de este trabajo, sumados a los ya realizados por otras investigaciones, proporcionen un relato más completo del desarrollo histórico de la farmacia y de los medicamentos, y coadyuven a la comprensión de la importancia de llevar a cabo estudios de historia de la ciencia y la tecnología.

\section{FUENTES}

Archivos

AHSSA, Fondo Salubridad Pública, Sección Inspección de Farmacias.

\section{Hemerografía}

American Druggist and Pharmaceutical Record, Nueva York, EUA.

Therapeutic Notes.

El Tiempo, ciudad de México, México.

El Imparcial, ciudad de México, México.

La Farmacia, periódico de la Sociedad Farmacéutica Mexicana, ciudad de México, México.

El Informador, ciudad de México, México.

Gaceta Médica de México, Órgano de la Academia Nacional de Medicina, ciudad de México, México.

Boletín del Instituto Patológico, ciudad de México, México.

\section{Bibliografía}

Aceves, Patricia, Liliana Schifter y Angélica Morales, "La farmacología nacional y la farmacopea mexicana”, en João Rui Pita y Ana Leonor Pereira (coord.), Histórias da saúde. Estudos do século Xx, Coimbra, Imprensa da Universidade de Coimbra, 2012, p. 199-216.

American Pharmaceutical Association, The National Formulary, 4a. ed., Philadelphia, J. B. Lippincott Company, 1919.

Armendaris, Eduardo, "Una visita a la Casa de Parke y Davis, en Detroit, Mich., E. U. A.", en R. Aguilar y Santillán (ed.), Memorias de la Sociedad Científica "Antonio Alzate", México, Imprenta del Gobierno Federal, 1908, p. 29-35. 
BARONI, E., "El clorhidrato de morfina para uso hipodérmico”, La Farmacia, v. 11, n. 3, 15 de marzo de 1902, p. 55-59.

Bezanilla Testa, Triunfo, "La industria farmacéutica nacional", Farmacoterapia, v. 1, n. 1, 1947, p. 6-7.

ESTEVA De SAGRera, Juan, Historia de la farmacia: los medicamentos, la riqueza y el bienestar, Barcelona, Masson, 2005.

FLores, Leopoldo, “Junta mensual del 31 de octubre de 1905", Anales del Instituto Médico Nacional, n. 7, 1905, p. 429-439.

"Junta mensual del 30 de abril de 1908", Anales del Instituto Médico Nacional, n. 10, 1908, p. 143-146.

Godínez Reséndiz, Rogelio, y Patricia Aceves Pastrana, "La regulación del medicamento industrial en México (1926-1937)”, Revista Mexicana de Ciencias Farmacéuticas, v. 43, n. 1, 2012, p. 49-57.

"El surgimiento de la industria farmacéutica en México (1917-1940)", Revista Mexicana de Ciencias Farmacéuticas, v. 45, n. 2, 2014, p. 55-68.

, Proyectos, realidades y utopías: la transformación de la farmacia en México (1919-1940), México, Universidad Autónoma Metropolitana-Unidad Xochimilco, División de Ciencias Biológicas y de la Salud, 2014.

Godínez Reséndiz, Rogelio, Patricia Aceves Pastrana, Juan Manuel Corona Alcántar y Nicolás Cárdenas García, "Introducción de los antibióticos en México: investigación científica y producción industrial (1944-1955)”, Llull, Revista de la Sociedad Española de Historia de las Ciencias y de las Técnicas, v. 39, n. 83, 2016, p. 103-133.

Hinke, Nina, El Instituto Médico Nacional. La política de las plantas y los laboratorios a finales del siglo XIX, México, Universidad Nacional Autónoma de México, Coordinación de Humanidades/Instituto Politécnico Nacional, Centro de Investigación y de Estudios Avanzados, 2012.

Instituto Médico Nacional, Farmacología nacional, México, Tipografía Económica, 1913.

IRIARTE y RiCo, Antonio, Evolución de la farmacia en México durante el primer siglo de nuestra independencia, México, Tipografía Vda. de F. Díaz de León, Sucs., 1911.

Lackenbach, Fred I., “Ampoules”, California State Journal of Medicine, v. 8, n. 9, 1910, p. 316-317.

Liebenau, Jonathan M., "Scientific Ambitions. The Pharmaceutical Industry, 19001920", Pharmacy in History, v. 27, n. 1, 1985, p. 3-11.

Limousin, Stanislas, “Ampoules hypodermiques. Nouveau mode de préparation des solutions pour les injections hypodermiques”, Bulletin Général de Thérapeutique Médicale et Chirurgicale, v. 110, n. 7, 1886, p. 316-319. 
Martínez Solís, Sandra, Patricia Aceves Pastrana y Alba Morales Cosme, "La transformación de una profesión: las primeras farmacéuticas mexicanas”, en México en el siglo Xx, México, Archivo General de la Nación, 1999, p. 613-638.

Mayo, Caswell A., "Ampuls - Their Use in the Dispensing of Hypodermic Solutions”, en American Pharmaceutical Association (ed.), Proceedings of the American Pharmaceutical Association, Baltimore, American Pharmaceutical Association, 1909.

, "The Ampul and Its Uses in the Preservation of Sterile Solutions", en American Pharmaceutical Association (ed.), Proceedings of the American Pharmaceutical Association, Baltimore, American Pharmaceutical Association, 1909, p. 1106-1117.

McConnell Sanders, James, “Departamento de Química Industrial”, Anales del Instituto Médico Nacional, v. 10, 1908, p. 127.

Morales Cosme, Alba Dolores, y Carlos Viesca Treviño, "El Laboratorio Químico Farmacéutico de T. Bezanilla e Hijos, 1905-1919”, Boletín de la Sociedad Química de México, v. 9, n. 3, 2015, p. 16-21.

National Convention for Revising the Pharmacopoeia, The Pharmacopoeia of the United States of America, Sixth decennial revision, New York, William Wood \& Company, 1883.

Nitardy, Ferdinand William, "Practical Pharmacy Methods and Devices", The Journal of the American Pharmaceutical Association, v. 2, n. 3, 1913, p. 314-324. , "Profit and Professional Advantages of Pharmaceutical Manufacturing by the Retail Pharmacist", The Journal of the American Pharmaceutical Association, v. 4, n. 7, 1915, p. 804-813.

North, Herman H., "Ampuls", The Journal of the American Pharmaceutical Association, v. 4, n. 5, 1915, p. 567.

OrTiz ReYnoso, Mariana, "Farmacia química en el siglo XIX mexicano: una mirada a través de los alcaloides”, en Angélica Morales Sarabia y Mauricio Sánchez Menchero (coord.), Signa naturalia: concepciones y prácticas en torno a la materia médica, la farmacia y la salud (siglos XVI-XX), México, Universidad Nacional Autónoma de México, Centro de Investigaciones Interdisciplinarias en Ciencias y Humanidades, 2016, p. 163-197.

Ortiz Reynoso, Mariana, Martha Díaz Flores, Hariz Islas Flores, Liliana Schifter Aceves, “Técnicas e instrumentos químico-farmacéuticos en México (18491925)”, Ciencia Ergo-Sum, v. 24, n. 1, 2017, p. 54-64.

PARKe, DAVIS \& Company, Physician's Manual of Therapeutics: Referring Especially to the Products of the Pharmaceutical and Biological Laboratories of Parke, Davis \& Company, Detroit, Parke, Davis \& Company, 1901. 
, Catalogue of the products of the Laboratories of Parke, Davis \& Company, London, Parke, Davis \& Company, 1907-1908.

, Manual of Therapeutics: Referring Especially to the Products of the Pharmaceutical and Biological Laboratories of Parke, Davis \& Company, Detroit, Parke, Davis \& Company, 1909.

PÉrez, Luis F., "De la esterilización de las soluciones de clorhidrato de cocaína”, La Farmacia, v. 14, n. 11, 15 de noviembre de 1905, p. 243-251.

Puerto, Francisco Javier, y Antonio González Bueno, Compendio de historia de la farmacia y legislación farmacéutica, Madrid, Síntesis, 2011.

Ramírez Rancaño, Mario, "El Primer Congreso de Industriales y la Constitución Política”, en Julio Labastida et al. (comp.), Grupos económicos y organizaciones empresariales en México, México, Alianza Editorial Mexicana/Universidad Nacional Autónoma de México, Instituto de Investigaciones Sociales, 1986, p. 83-122.

Rodríguez de Romo, Ana Cecilia, "La ciencia pasteuriana a través de la vacuna antirrábica: el caso mexicano”, Dynamis, n. 16, 1996, p. 291-316.

Rodríguez, Martha Eugenia, "La Escuela Nacional de Medicina en los tiempos del centenario”, Revista Médica del Instituto Mexicano del Seguro Social, v. 48, n. 4, 2010, p. 405-414.

Rodríguez Nozal, Raúl, Uriach, Cambronero, Gallego. Farmacia e industria. La producción de los primeros medicamentos en España, Madrid, Nivola, 2004.

, "Saturnino Cambronero González (1867-1927): sus aportaciones a la sanidad y a la tecnología del inyectable”, en Juan Esteva de Sagrera y Antonio González Bueno (ed.), Cordialero de libros y medicamentos. Homenaje al Dr. José María Suñé Arbussà, Madrid, Sociedad de Docentes Universitarios de Historia de la Farmacia de España, 2009, p. 225-246.

Rodríguez Nozal, Raúl, y Antonio González Bueno, Entre el arte y la técnica. Los orígenes de la fabricación industrial del medicamento, Madrid, Consejo Superior de Investigaciones Científicas, 2005.

Rodríguez Nozal, Raúl y Antonio González Bueno, "Historia del medicamento industrial: la irrupción de cápsulas, comprimidos e inyectables en la farmacia española”, Industria Farmacéutica, n. 11, 2005, p. 98-104.

Schaut, Robert A., y W. Porter Weeks, "Historical Review of Glasses Used for Parenteral Packaging”, Journal of Pharmaceutical Science and Technology, v. 71, n. 4, 2017, p. 279-296.

Schifter, Liliana, y Patricia Aceves, "Los farmacéuticos y la química en México (1903-1919): prácticas, actores y sitios”, Estudios de Historia Moderna y Contemporánea de México, n. 51, enero-junio 2016, p. 72-92.

Secretaría de la Economía Nacional, Dirección General de Estadística, "Productos farmacéuticos", en Tercer Censo Industrial de los Estados Unidos 
Mexicanos, México, Secretaría de la Economía Nacional, Dirección General de Estadística, 1944, p. 7-41.

Sociedad Farmacéutica Mexicana, Nueva farmacopea mexicana de la Sociedad Farmacéutica Mexicana, México, Oficina Tipográfica de la Secretaría de Fomento, 1896.

, Nueva farmacopea mexicana de la Sociedad Farmacéutica Mexicana, México, Oficina Tipográfica de la Secretaría de Fomento, 1904.

Swann, John P., "The Evolution of the American Pharmaceutical Industry", Pharmacy in History, v. 37, n. 2, 1995, p. 76-86.

Tainter, Maurice L., y G. M. A. Marcelli, "The Rise of Synthetic Drugs in the American Pharmaceutical Industry", Bulletin of the New York Academy of Medicine, v. 35, n. 6, 1959, p. 387-405.

"Una visita al Laboratorio El Águila”, La Farmacia, v. 2, n. 5, 1919, p. 86.

United States Pharmacopoeial Convention, The Pharmacopoeia of the United States of America, eighth decennial revision, Philadelphia, J. B. Lippincott Company, 1905.

, The Pharmacopoeia of the United States of America, ninth decennial revision, Philadelphia, J. B. Lippincott Company, 1916.

Urbina, Manuel, “Trabajo inaugural”, La Farmacia, v. 13, n. 11, 1904, p. 225-233.

URIBE Romo, E., "Nuevas perspectivas en el comercio internacional de medicinas a causa de la guerra”, Revista de Economía, v. 1, n. 8, 1940, p. 37.

Villaseñor, Federico F., "Algunas consideraciones acerca del suero fisiológico artificial”, La Farmacia, v. 10, n. 3, 1901, p. 73-87. 